\title{
First-line management of canine status epilepticus at home and in hospital- opportunities and limitations of the various administration routes of benzodiazepines
}

\author{
Marios Charalambous ${ }^{1 *}$ (D) Holger A. Volk², Luc Van Ham ${ }^{1}$ and Sofie F. M. Bhatti ${ }^{1}$
}

\begin{abstract}
Status epilepticus (SE) or prolonged epileptic seizure activity is a common neurological emergency with a high mortality rate and, if left untreated, can lead to irreversible cerebral damage and systemic complications. Fast and effective first-line management is of paramount importance, particularly in the at-home management of seizures where drug administration routes are limited. Benzodiazepines (BZDs) have been exclusively used in veterinary medicine for decades as first-line drugs based on their high potency and rapid onset of action. Various administration routes exist in dogs, such as oral, intravenous, intramuscular, rectal, and intranasal, all with different advantages and limitations. Recently, intranasal drug delivery has become more popular due to its unique and favourable characteristics, providing potential advantages over other routes of drug administration in the management of canine SE. This narrative review provides an outline of the management of SE at home and in a hospital setting, discusses considerations and challenges of the various routes of BZD administration, and evaluates the impact of intranasal drug administration (nose-brain pathway) for controlling canine SE at home and within hospital settings.
\end{abstract}

Keywords: Dog, Emergency seizures, Epilepsy, Administration routes, Midazolam, Diazepam, Nasal

\section{Background}

Although most epileptic seizures are self-limiting and last for a few seconds or minutes (usually $<2-3 \mathrm{~min}$ ), in some cases seizures can be prolonged leading to the development of status epilepticus (SE) [1]. SE is broadly defined clinically as seizures lasting $>5$ min or multiple seizures with incomplete inter-seizure recovery and remains a common neurological emergency [1-3]. In selflimiting seizures, an array of processes lead to seizure termination including i) excitatory neurotransmitter (glutamate) and ATP depletion, ii) enhanced $\gamma$ -

\footnotetext{
* Correspondence: marios.charalambous@ugent.be

${ }^{1}$ Small Animal Department, Faculty of Veterinary Medicine, Ghent University, 9820 Merelbeke, Belgium

Full list of author information is available at the end of the article
}

aminobutyric acid (GABA)-induced inhibition, iii) adenosine release, iv) ionic (calcium, potassium) level alterations, and v) acidification of intra- and extracellular space [4]. Insufficiency of the seizure termination mechanisms and imbalance between excitatory and inhibitory activity within the forebrain's neuronal network may lead to SE in both humans and animals $[5,6]$. In addition, other mechanisms that promote seizure activity during SE include inflammatory processes (e.g. interleukins), enhanced pro-epileptogenic peptide expression (e.g. substance P), and blood-brain barrier (BBB) dysfunction [7-11].

SE can occur in dogs with idiopathic epilepsy (IE), structural epilepsy or reactive seizures [12-14]. In general, $0.5-2.6 \%$ of dogs are admitted to the emergency 
hospital for SE $[15,16]$. Among the population of dogs presenting to hospital for seizures, $16.5 \%$ manifest SE [12] and the latter has been identified as the first clinical manifestation of an epileptic seizure disorder in 58\% of dogs [16]. Studies showed that 32-40\%, 27-59\%, and 7$23 \%$ of dogs with structural epilepsy, IE, and reactive seizures, respectively, can present with SE $[12-14,16]$. SE can lead to permanent brain damage (e.g. neuronal cell necrosis, network reorganization, gliosis) and severe systemic complications (e.g. cardiorespiratory collapse, shock, acidosis, electrolyte imbalances) [5]. The occurrence and severity of SE-induced complications are proportionally related to the duration of seizure activity [17-21]. With regard to the survival rates, an overall mortality rate of $25.3-38.5 \%$ among all dogs presented with SE has been reported $[12,16]$. Therefore, clinicians or owners should quickly intervene to cease the continuous seizure activity either in hospital or at home, respectively [22-25]. Owners, in particular, have a substantial role in seizure control because appropriate administration of antiseizure drugs at home could prevent seizure progression to SE or reduce the risk of progression to more refractory stages. First-line management is of paramount importance and should include drugs with high potency and rapid onset of action. The aims of first-line management are i) cessation of seizures, ii) prevention of SE refractory phases, iii) prevention of complications, and iv) avoidance of adjunction of anaesthetic and non-anaesthetic antiseizure medications that could increase the risk of adverse effects [24]. Benzodiazepines (BZDs) have been exclusively used for decades in humans and animals as first-line antiseizure treatment due to their high potency and rapid onset of action [22-25].
The primary goals of this review are to i) provide an outline about the management of SE at home and in the hospital, with particular focus on first-line pharmacological intervention, ii) discuss the considerations and challenges of the various routes of BZD administration, iii) analyse and evaluate the recently introduced intranasal (IN) drug delivery method for controlling SE in dogs, and iv) provide guidance for primary and specialist clinicians regarding SE management within home and hospital settings.

\section{Therapeutic considerations in status epilepticus}

SE therapy should incorporate a combination of medical interventions including antiseizure medication and measurements for treating seizure-related complications (e.g. intravenous fluid therapy for addressing in case of electrolyte imbalances) and underlying aetiological conditions (e.g. radiotherapy or surgical therapy in case of brain neoplasia, immunosuppressive therapy in case of immune-mediated meningoencephalitis) $[5,26]$. Regarding seizure activity termination, SE may be subdivided into four different stages (Fig. 1), which differ in terms of sensitivity to the drugs used, treatment options as well as morbidity and mortality rates $[17,19,20,27-31]$ :

- Impending SE

- Less than 5 min of continuous seizure activity.

- Seizures are most likely responsive solely to firstline antiseizure therapy.

- Established SE

- Less than 30 min of continuous seizure activity.

- Seizures are still, but likely less, responsive to first-line antiseizure therapy.

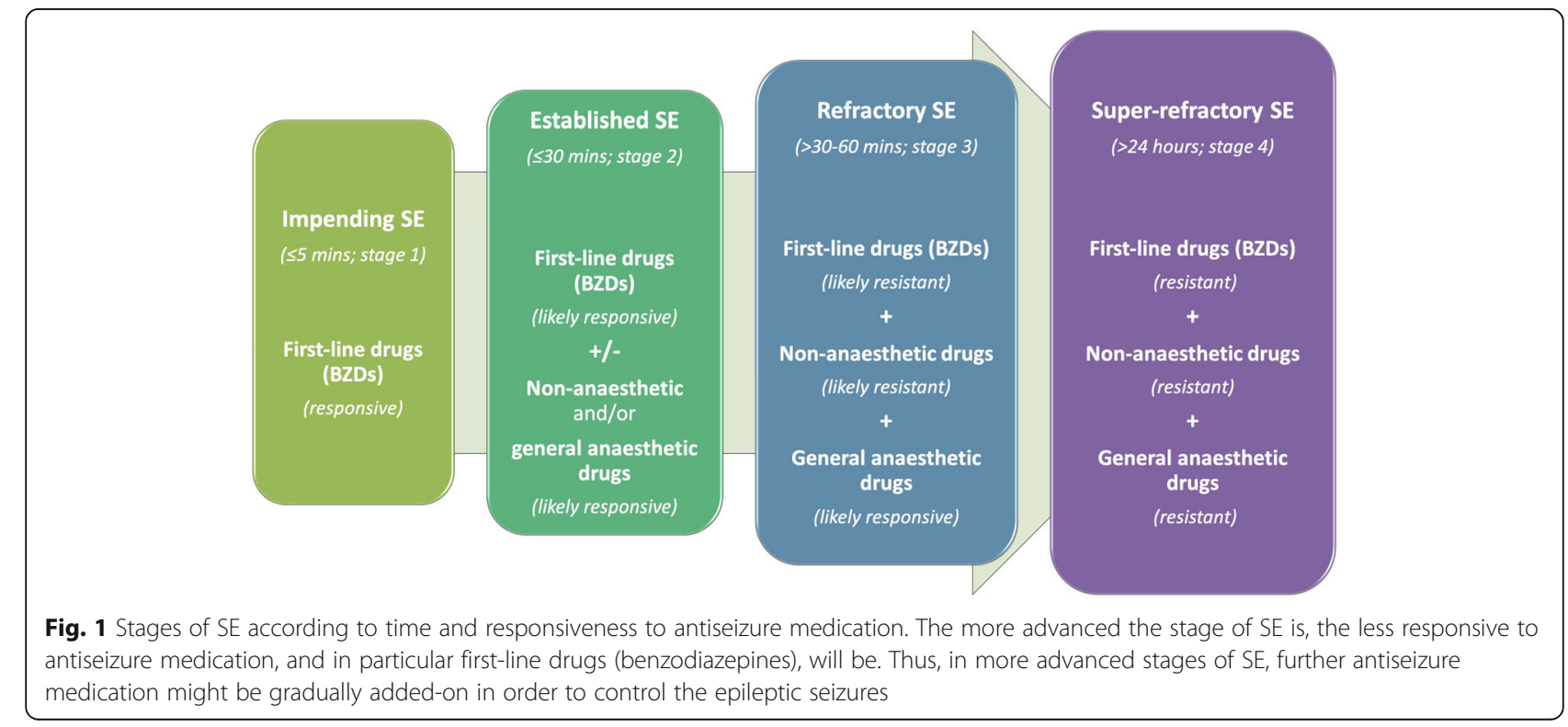


- Adjunctive non-anaesthetic (e.g. phenobarbital, levetiracetam) or general anaesthetic (e.g. propofol, ketamine, pentobarbital, etomidate, inhalation anaesthetics) antiseizure therapy might be needed.

- Refractory SE

- Less than 30-60 min of continuous seizure activity.

- Seizures are resistant to first-line and nonanaesthetic antiseizure therapy.

- Adjunctive general anaesthetic antiseizure therapy is needed.

- Super-refractory

- More than $24 \mathrm{~h}$ of continuous seizure activity or seizure recurrence after initiation of treatment with general anaesthetic antiseizure therapy.

- Seizures are likely resistant to any antiseizure therapy.

The reasons SE progresses towards more refractory stages over time are related to multiple processes that inhibit cessation of activity including mainly i) loss of GABA-induced inhibition, ii) upregulation of excitation induced by $\mathrm{N}$-methyl-d-aspartate (NMDA) and $\alpha$ amino-3-hydroxy-5-methyl-4-isoxazolepropionic acid (AMPA) receptors for glutamate, and iii) BBB transporters overexpression [6, 32]. GABAergic drugs (e.g. benzodiazepines (BDZs)) are particularly used in the management of SE [24, 25]. BZD's effects derive from their action on pre- and postsynaptic GABA-ergic transmission; specifically, they bind on the $\gamma$-subunit of $\mathrm{GABA}_{\mathrm{A}}$ receptors, enhancing the inhibitory effect of GABA, and result in an opening of chloride channels and influx of chloride within the neurons. This effect leads to hyperpolarisation of the cell membrane and inhibition of the transmission of nerve impulses [30, 33]. BZDs' effectiveness, though, may gradually decrease with prolonged SE due to reduced synaptic targets (e.g. internalization of $\mathrm{GABA}_{\mathrm{A}}$ receptors $\gamma$-subunits, alterations in $\mathrm{GABA}_{\mathrm{A}}$ receptor trafficking and conversion of receptors subunits to less BZD-responsive) and changes in chloride homeostasis [34, 35]. Medications that act also on other external subunits (e.g. $\alpha, \beta)$ of $\mathrm{GABA}_{\mathrm{A}}$ receptors (e.g. phenobarbital, propofol, inhalation anaesthetics) should be more efficient in cases of BZDresistant SE [36-38]. In (super) refractory SE, resistance to most of $\mathrm{GABA}_{\mathrm{A}}$-acting drugs may occur due to several factors including phosphorylation and internalization of the potassium-chloride transporter and increased concentration of intracellular chloride [39]. In addition, loss of AMPA receptors $\mathrm{GluA}_{2}$ subunit and overexpression of NMDA receptors occur, which promote glutamate-induced excitation [40, 41]; these changes lead to calcium accumulation within the cells and trigger apoptosis [41]. Glutamate receptor (NMDA) antagonists (e.g ketamine) may be beneficial particularly in refractory stages of SE and they may even help preventing resistance, if administered at early stages [6]. Overexpression and activation of NMDA receptors may also contribute towards calcineurin-induced internalization of the $\mathrm{GABA}_{\mathrm{A}}$ receptors $\gamma$-subunits, leading further to BZD resistance $[42,43]$. Therefore, NMDA receptor inhibitors may also have another benefit by means of enhancing BZDs potency as it was observed in animal models for SE [44-46]. Another process that occurs during $\mathrm{SE}$ is the overexpression of BBB drug transporters, which results in pharmaco-resistance [47]. A significant upregulation by $87-166 \%$ of endothelial P-glycoprotein (PGP; BBB drug transporter) was demonstrated in the canine brain following SE that leads to enhanced BBB efflux of antiseizure drugs and limited concentrations of drugs into the brain [48]. Lastly, after prolonged seizure activity, alterations in gene expression and associated protein production responsible for drug transporters as well as reorganization of synapses occur; all these processes contribute further to the drug resistance as it was shown in animal and human studies [17, 49, 50]. Therefore, the early application of drugs with different mechanisms of action (e.g. GABA $\mathrm{A}_{\mathrm{A}}$ agonists and NMDA antagonists) and through different routes (e.g. administration routes that might avoid $\mathrm{BBB}$ ) with the aim to circumvent the mechanisms that sustain continuous seizure activity is fundamental for the management of SE (Fig. 2).

\section{Benzodiazepines}

Diazepam (DZP), midazolam (MDZ), and lorazepam (LZP) are the main representatives of BZDs used as first-line treatment of SE [22-25]. In veterinary medicine, MDZ and DZP have been mainly used, although only DZP is currently licenced for small animals. In dogs, both DZP and MDZ can be effective for ceasing seizure activity, but this can depend on the administration route and dose [5, 22, 23, 25]; the recommended dose ranges for MDZ or DZP remain the same regardless the route of administration. Although not welldefined, it has been estimated that DZP should reach serum concentration of $0.15-0.5 \mu \mathrm{g} / \mathrm{mL}[33,51-53]$ within $10-15 \mathrm{~min}$ in order to provide a clinically acceptable seizure control in canine SE and prevent progression to more refractory stages. For MDZ, these values have not been established for dogs, but it is speculated from human medicine that serum concentration of < $0.04 \mu \mathrm{g} / \mathrm{mL}$ might be adequate for seizure cessation [54]. In addition, MDZ might be potentially more potent than DZP because, in one canine study, MDZ manifested a higher suppressive effect on lidocaine-induced epileptic 


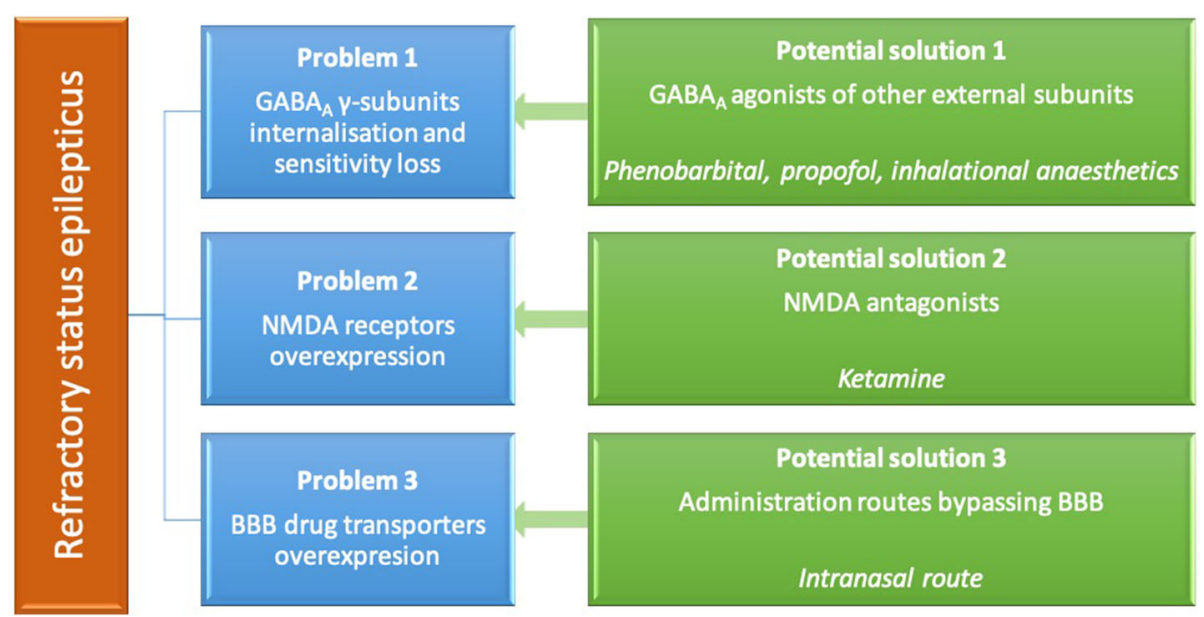

Fig. 2 Summary of the main causes of pharmaco-resistance in refractory stages of SE and potential solutions to them

seizures compared to DZP [55]. In a human pharmacodynamic and encephalographic study, MDZ was found to be 5-6 times more potent than DZP [56]. In addition, MDZ has gained more popularity in the management of SE due to its safer drug profile, i.e. MDZ-induced brain and respiratory depression are less severe compared to DZP and LZP [30].

MDZ is a hydrophilic drug but converts to lipophilic at physiologic $\mathrm{pH}$ (e.g. tissues), which facilitates penetration of BBB [30,56]. MDZ can be administered at a dose of $0.2-0.5 \mathrm{mg} / \mathrm{kg}$ IV, IN or intramuscular (IM) but has a short half-life (approximately $1 \mathrm{~h}$ in the dog), and thus, frequent administration or constant rate infusion (CRI) might be necessary for adequate seizure control $[5,25]$. An IV CRI at the dose of $0.2-0.5 \mathrm{mg} / \mathrm{kg} / \mathrm{h}$ might be advised to sustain good seizure control after the delivery of the initial MDZ bolus dose [5, 25]. The CRI dose is administered via an infusion pump and usually diluted in $0.9 \%$ saline or $5 \%$ dextrose solution, with the volume used being equal to the dog's hourly maintenance fluid requirements [5, 25]. The dosage rate should be reduced by $50 \%$ every $6 \mathrm{~h}$ for at least two times before discontinuation of the drug $[5,25]$. In humans, it has been shown that MDZ's half-life increases after CRI [57].

DZP is a lipophilic drug, which can also penetrate the BBB [30,56]. Because of its lipophilicity, it is prepared in propylene glycol, which can induce phlebitis and hypotension, especially when rapidly administered [5]. Therefore, central IV access may be needed for preventing phlebitis, although establishing such an access might be quite challenging and time-consuming during SE [5]. DZP can also adsorb to plastic and, therefore, should not be stored in plastic syringes or infusion lines for any length of time [58]. DZP may be administered as a bolus at the dose of $0.5-2.0 \mathrm{mg} / \mathrm{kg} \mathrm{IV}$, IN or rectally (R) [5,
25]. Repeat DZP bolus leads to accumulation and high concentrations of the drug in the central nervous system (CNS), cerebrospinal fluid (CSF), and serum; although this may result in prolonged antiseizure activity, it can also cause severe CNS depression and cardiorespiratory collapse [59]. Therefore, only 2-3 DZP boluses should be considered and, if unsuccessful, an IV CRI (at the dose of $0.1-0.5 \mathrm{mg} / \mathrm{kg} / \mathrm{h}$ ) or another antiseizure drug should be considered $[5,25]$. Co-administration of levetiracetam enhances DZP's antiseizure effect and, thus, DZP's dose adjustment might be needed [60]; this phenomenon might also occur with the combination of levetiracetam and other BDZs [61].

\section{Administration routes}

Various administration routes have been studied in human and veterinary medicine for managing SE either at home or in hospital. One of the main challenges is the at-home management of emergency seizures as therapeutic options and routes of administration are quite limited and restricted to non-IV routes of administration. Given the fact that SE management should be commenced at the earliest possible, there is an undoubted need for quickly effective routes of administration that can be applied in the out-of-hospital environment by owners or even clinicians within hospital settings (especially when IV line has not been yet established) [62]. Advantages and challenges of the various administration routes are discussed below and summarised in Table 1. Information regarding each BZD's recommended dose and target serum concentration as well as reported serum concentrations, time to peak serum concentrations and time to seizure control achieved with each administration route in dogs is provided in Table 2. 
Table 1 Advantages and limitations of benzodiazepines delivery routes in dogs

\begin{tabular}{|c|c|c|}
\hline Administration route & Advantages & Limitations \\
\hline Intravenous & $\begin{array}{l}\text { Likely effective (clinical evidence) } \\
\text { Likely rapid onset of action (clinical evidence) } \\
\text { Precise control of the administered dose } \\
\text { Avoidance of first-pass hepatic metabolism }\end{array}$ & $\begin{array}{l}\text { Subject to blood-brain barrier } \\
\text { Requirement for hospitalisation } \\
\text { Requirement for medically-trained staff } \\
\text { Hard to establish during seizures } \\
\text { Not for at-home use }\end{array}$ \\
\hline Intramuscular & $\begin{array}{l}\text { Likely favourable pharmacokinetics } \\
\text { Avoidance of first-pass hepatic metabolism }\end{array}$ & $\begin{array}{l}\text { Subject to blood-brain barrier } \\
\text { Requirement for training or medical staff } \\
\text { Needle/syringe misuse by non-trained caregivers } \\
\text { Less suitable for at-home use } \\
\text { Soft tissue or nerve damage risk } \\
\text { Infection risk } \\
\text { Painful }\end{array}$ \\
\hline Transdermal & $\begin{array}{l}\text { Painless } \\
\text { Easy to use } \\
\text { Suitable for home } \\
\text { No requirement for medical training } \\
\text { Avoidance of first-pass hepatic metabolism }\end{array}$ & $\begin{array}{l}\text { Subject to blood-brain barrier } \\
\text { Slow release not suitable for emergency }\end{array}$ \\
\hline Buccal & $\begin{array}{l}\text { Painless } \\
\text { Ease to administer } \\
\text { Suitable for home } \\
\text { No requirement for medical training } \\
\text { Avoidance of first-pass hepatic metabolism }\end{array}$ & $\begin{array}{l}\text { Subject to blood-brain barrier } \\
\text { Potentially unfavourable pharmacokinetics } \\
\text { Delivery of limited drug amount } \\
\text { If swallowed, functions as oral } \\
\text { Dog's compliance is needed } \\
\text { Incorrect administration during seizures }\end{array}$ \\
\hline Sublingual & Similar to buccal & Similar to buccal \\
\hline Oral & $\begin{array}{l}\text { Painless } \\
\text { Easy to use } \\
\text { No requirement for medical training } \\
\text { Suitable for home }\end{array}$ & $\begin{array}{l}\text { Subject to blood-brain barrier } \\
\text { Potentially unfavourable pharmacokinetics } \\
\text { Slow absorption not suitable for emergency } \\
\text { Potential for gastrointestinal degradation } \\
\text { Subject to first-pass hepatic metabolism } \\
\text { Dog's compliance is needed }\end{array}$ \\
\hline Rectal & $\begin{array}{l}\text { Minimal pain/discomfort } \\
\text { Relatively easy to use } \\
\text { No requirement for medical training } \\
\text { Suitable for home }\end{array}$ & $\begin{array}{l}\text { Subject to blood-brain barrier } \\
\text { Variability in effectiveness (clinical evidence) } \\
\text { Variability in pharmacokinetics } \\
\text { Partially subject to first-pass hepatic metabolism } \\
\text { Likely slow onset of action } \\
\text { Socially unacceptable }\end{array}$ \\
\hline Intranasal & $\begin{array}{l}\text { Likely effective (clinical evidence) } \\
\text { Likely rapid onset of action (clinical evidence) } \\
\text { Likely favourable pharmacokinetics } \\
\text { Avoidance of first-pass hepatic metabolism } \\
\text { Avoidance of blood-brain barrier } \\
\text { No requirement for medical training } \\
\text { Relatively easy to use } \\
\text { Painless } \\
\text { Suitable for home }\end{array}$ & $\begin{array}{l}\text { Need for high concentration drug } \\
\text { Potentially affected by mucosal factors } \\
\text { Potentially affected by drug formulation } \\
\text { Need for a veterinary nasal device }\end{array}$ \\
\hline
\end{tabular}

\section{Intravenous}

IV administration of BZDs has an onset of action approximately within $<2-7 \mathrm{~min}$, circumvents first-pass hepatic metabolism (i.e. i.e. liver-induced drug metabolism whereby the concentration of a drug might be substantially reduced) [30,56], and is likely effective for ceasing SE in humans [63-71] and dogs [23, 25, 33, 7274]. In humans, IV administration of BDZs has been considered the "gold standard" route as it can result in the highest drug efficacy and shorter seizure cessation time [75-77]; similar recommendations have been made in dogs $[25,78]$. In clinical practice, however, delays in establishing IV access in a seizuring human [79-81] or $\operatorname{dog}[23,72]$ can be significant and negatively affect IV drugs' onset of action. Based on a systematic review/ meta-analysis in humans, non-IV BDZs could be administered faster to patients and demonstrated superior efficacy and onset of action in terminating seizures compared to IV-BDZs [79]. In veterinary medicine, there are not enough clinical trials to allow the conduction of a systematic review/meta-analysis evaluating and comparing different BDZ or IV versus non-IV routes of administration, but it is likely that the experience and evidence derived from human medicine could be translated to veterinary medicine. Existing clinical data, though, already indicates that IV route, despite being 
Table 2 Information regarding each benzodiazepine's recommended dose and target serum concentration as well as reported serum concentrations, time to peak serum concentration and time to seizure control achieved with each administration route in dogs

\begin{tabular}{|c|c|c|}
\hline & Midazolam & Diazepam \\
\hline Recommended dose & $\begin{array}{l}0.2-0.5 \mathrm{mg} / \mathrm{kg} \text { intravenous, } \\
\text { intranasal or intramuscular }\end{array}$ & $0.5-2.0 \mathrm{mg} / \mathrm{kg}$ intravenous, intranasal or rectal \\
\hline $\begin{array}{l}\text { Recommended target serum concentration for seizure } \\
\text { control (pharmakokinetic studies) }\end{array}$ & $\begin{array}{l}<0.04 \mu \mathrm{g} / \mathrm{mL} \text { (value derived } \\
\text { from humans) }\end{array}$ & $0.15-0.5 \mu \mathrm{g} / \mathrm{mL}$ \\
\hline \multirow{12}{*}{$\begin{array}{l}\text { Serum concentration achieved with each administration } \\
\text { route (pharmakokinetic studies) }\end{array}$} & Intravenous & \\
\hline & NA & NA \\
\hline & Intranasal & \\
\hline & $\begin{array}{l}0.21 \pm 0.02 \mu \mathrm{g} / \mathrm{mL} \text { (solution) or } \\
0.45 \pm 0.09 \mu \mathrm{g} / \mathrm{mL} \text { (gel) }\end{array}$ & $\begin{array}{l}0.44 \pm 0.04 \mu \mathrm{g} / \mathrm{mL} \text { (solution) or } 0.31+/-0.17 \\
\text { (solution/atomised formulation) }\end{array}$ \\
\hline & Intramuscular & \\
\hline & $\begin{array}{l}0.20 \pm 0.06 \mu \mathrm{g} / \mathrm{mL} \text { or } 0.55 \pm \\
0.12 \mu \mathrm{g} / \mathrm{mL} \text { (solution) }\end{array}$ & NA \\
\hline & Rectal & \\
\hline & NA & $\begin{array}{l}0.5 \mu \mathrm{g} / \mathrm{mL} \text { (solution) and or } 0.01-0.1 \mu \mathrm{g} / \mathrm{mL} \\
\text { (suppository) }\end{array}$ \\
\hline & Buccal & \\
\hline & $0.1-0.2 \mu \mathrm{g} / \mathrm{mL}(\mathrm{gel})$ & NA \\
\hline & & Sublingual \\
\hline & NA & NA \\
\hline \multirow{12}{*}{$\begin{array}{l}\text { Time to peak serum concentration achieved with each } \\
\text { administration route (pharmakokinetic studies) }\end{array}$} & & Intravenous \\
\hline & NA & NA \\
\hline & Intranasal & \\
\hline & 12 min (gel) or 17 min (solution) & 4.5-8.0 min (solution/atomised formulation) \\
\hline & Intramuscular & \\
\hline & 10-15 min (solution) & NA \\
\hline & Rectal & \\
\hline & NA & 15 min (solution) or 80 min (suppository) \\
\hline & Buccal & \\
\hline & $15 \min ($ gel) & NA \\
\hline & Sublingual & \\
\hline & NA & NA \\
\hline \multirow{12}{*}{$\begin{array}{l}\text { Time to seizure control achieved with each administration } \\
\text { route (clinical studies) }\end{array}$} & Intravenous & \\
\hline & $1.0-4.5 \mathrm{~min}$ & NA \\
\hline & Intranasal & \\
\hline & $0.5-1.6 \mathrm{~min}$ & NA \\
\hline & & Intramuscular \\
\hline & NA & NA \\
\hline & & Buccal \\
\hline & NA & NA \\
\hline & & Sublingual \\
\hline & NA & NA \\
\hline & & Rectal \\
\hline & NA & $2.5 \mathrm{~min}$ \\
\hline
\end{tabular}


effective, might not be the "gold standard" delivery method as it was widely speculated up to date. Specifically, based on a recent multicenter clinical trial in canine SE, IV administration of MDZ was inferior to IN with regard to median seizure cessation time ( $1 \mathrm{~min}$ for IV versus $0.5 \mathrm{~min}$ for $\mathrm{IN}$ ), especially when the time needed to establish an IV catheter was considered $(4.5 \mathrm{~min}$ for IV versus $1.6 \mathrm{~min}$ for IN) [23]. The main factors in clinical practice that pose significant difficulties in establishing or maintaining functional IV access and delays in IV drug administration and seizure cessation include i) convulsive seizure activity, ii) requirement of experienced medically-trained staff, iii) patient's cardiovascular collapse, and iv) small or toy canine breeds $[23,68,72,79$, $82,83]$.

\section{Intramuscular}

IM BZDs provide onset of action within $15 \mathrm{~min}$ after administration and have been suggested for at-home and in-hospital SE management in humans [64, 66, 84-88]. IM administration is not subject to first-pass hepatic metabolism and has been also shown that IM administration of MDZ can be as effective as IV-DZP for the management of human SE [86, 87]. In two double-blinded randomised controlled clinical studies in humans, IM-MDZ could be administered by trained medical staff quicker and easier than and was as effective as IV-LZP $[64,66]$. Based on metaanalysis in humans, both IM and IN administration of BDZs have been shown to be two of the most effective and fastest methods for ceasing SE, especially in out-of-hospital settings $[69,89]$. Clinical trials to evaluate IM-BZDs' efficacy and safety have not been conducted in dogs, apart from pharmacokinetic studies [72, 73]. Specifically, after IM administration of MDZ solution (at the lowest clinically recommended dose of $0.2 \mathrm{mg} / \mathrm{kg}$ [72] or $0.5 \mathrm{mg} / \mathrm{kg}$ [73]), mean bioavailability was $50 \%$ [72] and $>90 \%$ [73]. The mean serum concentration was $0.20 \pm 0.06 \mu \mathrm{g} / \mathrm{mL}$ [72] or $0.55 \pm 0.12 \mu \mathrm{g} / \mathrm{mL}$ [73]. The maximum serum concentrations were achieved within $10-15 \mathrm{~min}$ [72, 73]. DZP is not advised to be given IM because of its erratic absorption [30].

In comparison to other non-IV routes, IM drug administration can be quite painful and pose risks [90], such as syringe/needle misuse, soft tissue or nerve injury, and administration in wrong sites or tissues, especially when administered by non-experienced, nonmedically-trained individuals, such as dog owners.

\section{Transdermal}

The transdermal drug administration is easily performed (no requirement for syringes or injections), not subject to first-pass hepatic metabolism, and could be a reasonable method for gradual and long-term delivery of drugs (lipophilic drugs with $<500 \mathrm{Da}$ molecular weight, such as BZDs, can penetrate through the skin layers and reach the systemic circulation) [91-93]. However, before therapeutic levels of any drug appear to the systemic circulation, drug crossing and accumulation through the dermal layers is necessary $[93,94]$; the latter depends on several factors such as pharmacological characteristics and delivery systems, skin thickness and barrier, and enzymes present in skin that degrade drugs [91-94]. Therefore, a rapid effect that is vital in emergency situations is unlikely in SE, even if permeation enhancers to increase drugs' absorption are co-administered [91, 92]. The transdermal route for administering long-term antiseizure drugs, i.e. levetiracetam or phenobarbital, has been reported in epileptic cats [95-97] but there is a lack of evidence regarding transdermal BZDs for treating emergency seizures in dogs, likely due to the limitations discussed above.

\section{Buccal}

Buccal-BZD might provide an alternative administration option in humans due to its relatively easy use (no requirement for syringes or injections) and the fact that it is socially acceptable (avoidance of rectal drug administration especially in public) [98]. Buccal MDZ has an onset of action within 5-10 min, avoids first-pass hepatic metabolism and has showed good efficacy and safety profile [98-104]. Based on a randomised controlled study, both buccal-MDZ and IV-DZP were successful in ceasing SE but IV-DZP had significantly better mean seizure cessation time $(1.1 \mathrm{~min})$ than buccal-MDZ (1.7 min); however, when the time to establish IV access was considered, buccal-MDZ demonstrated significantly shorter mean seizure cessation time $(2.4 \mathrm{~min})$ compared to IV $(3 \mathrm{~min})$, indicating that preparing the IV medication and introducing an IV line can delay the treatment [103]. According to a systematic review/meta-analysis, buccal-MDZ was more effective than R-DZP in ceasing seizures [69]. Buccal-MDZ, though, was not as effective and fast as IN-MDZ or IM-MDZ for terminating seizures, based on the conclusion of another systematic review/meta-analysis [89]. In dogs, only pharmacokinetic studies have been performed. One study showed that after buccal administration of various MDZ gel formulations (at the dose of $0.3 \mathrm{mg} / \mathrm{kg}$ ), bioavailability ranged from 25 to $41 \%$ [105], mean serum concentrations ranged from $0.1-0.2 \mu \mathrm{g} / \mathrm{mL}$ and time to peak concentration was achieved within $15 \mathrm{~min}$ [105]. Another study showed a pH-dependent absorption of buccal-BZDs, with bioavailability ranging from $6.2-22.6 \%$ [106]. No clinical trials to support its efficacy in canine SE exist up to date. 
Administering the correct dose via the buccal route poses limitations in humans (e.g. hypersalivation and risks of incomplete absorption and aspiration as well as need for patient's cooperation that might not be realistic in cases of SE) [107]; these limitations might be higher in dogs, adding the risk of the owners being bitten or injured. Additionally, buccal route is beneficial only for small drug doses and volumes as some amount of the buccally administered drug can be swallowed; the latter can lead to decreased bioavailability and delayed time to peak concentration mainly due to the first-pass hepatic metabolism and gastrointestinal tract absorption time, respectively $[108,109]$.

\section{Sublingual}

The sublingual route is another administration method within the oral cavity similar to buccal. The sublingual route provides a thinner and more permeable layer of absorption compared to buccal and, thus, could potentially provide a faster onset of action [110]. To benefit from this, it is essential that the drug should be administered in specific areas of the oral cavity, i.e. sublingual drugs are administered under the tongue, while buccal drugs at the caudal aspect of the oral cavity between the upper or lower molars and the cheek in humans. One of the main limitations in both routes is the necessity for cooperation of the patient for correct administration, which is quite challenging during SE and even more difficult or nearly impossible in dogs. The limitations mentioned in the buccal administration apply also in sublingual route. Absorption can also be very slow [111]. Therefore, sublingual and buccal drug delivery might not be ideal for humans and particularly dogs during seizures. This was also supported by one randomised controlled trial in 436 children showing that sublingual-LZP was less effective than R-DZP in managing seizures [112]. In dogs, no studies evaluating the sublingual BZDs administration have been performed.

\section{Oral}

Oral is considered a practical and easy (no requirement for syringes or injections) route of drug administration [113], although it might not be feasible during SE. Certain oral drugs including BZDs and in particular MDZ display low or variable bioavailability in humans (approximately $53-97 \%$ and $15-40 \%$ for DZP and MDZ, respectively) as well as reduced efficacy and quite prolonged onset of action (approximately 15-60 and 10-45 min for DZP and MDZ, respectively) due to their slow absorption and enzymatic degradation in the gastrointestinal system (small intestine and stomach), and extensive first-pass hepatic metabolism [113-121]. In addition, oral BZDs cannot be administered in people with difficulty in swallowing or have severe CNS suppression [122], as it occurs in SE, and may lead to aspiration pneumonia, especially after administering oily solutions such as DZP. Similar limitations exist in dogs, including the risk of caregiver's injury due to accidental dog bites, which impair the effect and use of oral BDZs in canine SE. BZDs' mean availability after oral administration in dogs is 69\% for MDZ [73] and $>70 \%$ for DZP [123]. Overall, oral BZDs are deemed inconvenient, risky as well as inadequate or ineffective in both human and canine SE.

\section{Rectal}

Rectal administration of BZDs and in particular DZP has been well recommended and widely used as a relatively cheap and potentially effective managing option in human SE, with an onset of action within 10-15 min [124, 125]. Rectal drugs can be administered by non-medically trained individuals in contrast to IM and IV drug delivery routes [117]. Empty rectum provides a stable environment with low activity of degrading enzymes that favours absorption of drugs into the systemic circulation [117], but faecal material may impair drug absorption. R-DZP has been suggested as a non-IV method of treating SE in humans, especially within out-of-hospital settings [102, 126-128]. Based on a systematic review/ meta-analysis the time periods from arrival in the hospital to drug administration and seizure cessation were shorter with IN, IM and buccal routes of MDZ administration compared to R-DZP [129]. Based on another meta-analysis, R-DZP was not considered as effective as other non-IV methods of MDZ administration and in particular IN- and IM-MDZ [89]. In a third systematic review, non-R BZDs routes of administration were suggested as better or preferred SE treatment options compared to R-DZP [130].

R-DZP in dogs has been widely recommended as a management option for SE in the absence of IV access. This recommendation has been mainly based on pharmacokinetic studies and one small-scale uncontrolled clinical trial $[51-53,131]$ with conflicting evidence. Specifically, after R administration of DZP (at the dose of 1 $\mathrm{mg} / \mathrm{kg}$ as solution [52] or $2 \mathrm{mg} / \mathrm{kg}$ as solution [53] or 2 $\mathrm{mg} / \mathrm{kg}$ as gel formulation/suppository [131]), mean bioavailability was reported to be $52 \%$ [52] or $7.4 \%$ [53] for the solution but was not detected for suppositories [131]. There was a notable variability in DZP serum concentrations among dogs but, in general, the mean serum concentration was approximately $0.5 \mu \mathrm{g} / \mathrm{mL}[52,53]$ for the solution and ranged between $0.01-0.1 \mu \mathrm{g} / \mathrm{mL}$ for the suppository [131]. The maximum serum concentrations were achieved within $15 \mathrm{~min}$ [52, 53] for the solution and $80 \mathrm{~min}$ [131] for the suppository. In addition, one recent multicenter open-labelled controlled clinical study compared R-DZP to IN-MDZ and showed that R- 
DZP was successful in terminating SE in only $20 \%$ of the dogs (versus $70 \%$ in the IN-MDZ group) and was significantly inferior to IN-MDZ [22]. Hence, R-DZP, in particular suppositories, might provide variable results and potentially inadequate seizure control within the time frame needed for successful control of SE. Regarding R administration of MDZ, studies report erratic bioavailability and serum concentration ranging from undetectable to low $[72,73]$. Therefore, MDZ is unlikely to be successful, but there are no clinical studies evaluating drug's effect in SE.

$R$ route of administration is generally not preferred by people due to cultural and social issues and the potential for discomfort and faecal or drug leakage out of the rectum [117]. Leakage of drugs together with other organic fluids can be an issue in dogs too, while application of rectal tubes might be difficult and performed incorrectly by the owners, especially during SE [22]. In addition, drugs can partially be subject to first-pass hepatic metabolism, which reduces their availability and increases their onset of action time [22, 117]. Given the fact that $\mathrm{R}$-DZP in dogs with SE is relatively inconvenient and likely less successful compared to other routes [22, 131], the promising value of alternative delivery methods (i.e. IN) was highlighted in the recent years [22, 23].

\section{Intranasal}

IN drug administration is a noninvasive method for delivering molecules and drugs aiming to act on local, systemic, and CNS level. IN delivery of BZDs offers multiple advantages because it i) requires minimum training and can be performed by non-medically trained individuals, ii) is easily executed, iii) carries minimal or no risk of injury for the owner, clinician or the dog (there were no reports of injury such as accidental bites of the personnel by the seizuring dog or trauma of the dog's nostrils during IN device application and drug administration), and iv) is generally well accepted for use at home compared to other non-IV routes [22, 23, 122].

The IN route provides fast and efficient drug delivery to the brain. Specifically, human studies reported that IN-MDZ (at the minimum clinically recommended dose of $0.2 \mathrm{mg} / \mathrm{kg}$ ) can reach the human brain and cease seizure activity within $2-5 \mathrm{~min}$, as shown on electroencephalography [132]. In addition, IN-MDZ at the same dose can reach serum concetration of $0.1-0.18 \mu \mathrm{g} / \mathrm{mL}$ to achive sedation within $12 \mathrm{~min}$ after administration (minimum therapeutic concentration for sedation in adult humans is $0.04 \mu \mathrm{g} / \mathrm{mL}$ ) [133-135]. It was suggested that the MDZ serum concentration needed to cease activity is even less compared to sedation in humans $(<$ $0.04 \mu \mathrm{g} / \mathrm{mL}$ ) [54]. IN-MDZ is also considered a good and successful alternative to other non-IV and IV routes of administration because its efficacy, safety and feasibility has been shown in multiple different species [22, 23, 122, 136-151]. Two human meta-analyses also strongly supported the effectiveness of IN-MDZ in SE $[69,89]$. In one meta-analysis, IN-MDZ was found to terminate $>90 \%$ of seizures within $5-10 \mathrm{~min}$ and sustain seizure freedom for minimum an hour in $80 \%$ of people with SE [89].

In humans, both MDZ and DZP can be effective and potent via IN delivery [80, 152-154]. When compared, DZP is more lipophilic than MDZ, which can result in DZP's better absorption by the nasal mucosa and potentially higher brain concentration [80, 152, 154]. However, DZP's high lipophilicity also causes the drug to be rapidly redistributed into peripheral tissues which eventually results in DZP's decreased concentration in the brain [80, 152]. MDZ demonstrates quicker rate of absorption by the nasal mucosa, but lower and more variable degree of absorption as well as shorter duration of action than DZP [80, 152-154]. However, MDZ's higher potency and better safety profile compared to DZP [30, $55,56]$ might make the drug a preferable choice in SE.

In veterinary medicine, pharmacokinetic studies showed that IN-MDZ $[155,156]$, IN-DZP $[33,157]$ and IN-flurazepam [156] are rapidly and efficiently absorbed by the nasal mucosa and can reach adequate therapeutic serum concentrations. Specifically, after IN administration of MDZ (lowest clinically recommended dose of $0.2 \mathrm{mg} / \mathrm{kg}$ ) and DZP (lowest clinically recommended dose of $0.5 \mathrm{mg} / \mathrm{kg}$ ), mean bioavailability was $52 \%$ (solution) [155] or $70.4 \%$ (gel formulation) [155] for MDZ and $80 \%$ (solution) [33] or $42 \%$ (solution/atomised formulation) [157] for DZP. The mean serum concentration was $0.21 \pm 0.02 \mu \mathrm{g} / \mathrm{mL}$ (solution) [155] or $0.45 \pm$ $0.09 \mu \mathrm{g} / \mathrm{mL}$ (gel formulation) [155] for MDZ and $0.44 \pm$ $0.04 \mu \mathrm{g} / \mathrm{mL}$ (solution) [33] or $0.31+/-0.17$ (solution/ atomised formulation) [157] for DZP. The maximum serum concentrations were achieved within $17 \mathrm{~min}$ (solution) [155] or $12 \mathrm{~min}$ (gel formulation) [155] for MDZ and $4.5 \mathrm{~min}$ (solution) [33] or $8 \mathrm{~min}$ (solution/atomised formulation) [157] for DZP. Regarding results from veterinary clinical studies, two recent open-labelled randomised controlled clinical trials demonstrated that INMDZ was not only safe and superior to R-DZP but also superior to the "gold standard" IV route of MDZ administration, especially when the time to place an IV catheter was considered $[22,23]$.

An important consideration regarding IN administration of BZD is that drugs' penetration into the brain and antiseizure effect can occur earlier than the time needed to reach maximum serum concentration [54, 155]. This can be supported by the fact that nasally administered drugs can follow both the blood systemic circulation and direct nerve pathways to reach the brain (as it will be thoroughly discussed later in the text); this may result in 
decreased drug concentration into the bloodstream, but successful penetration into the brain $[90,108,158]$. Therefore, estimating BZDs' therapeutic serum concentration and bioavailability after IN administration might not be an accurate tool for estimating drugs' efficacy, as it occurs with other administration routes.

\section{Nasal drug administration considerations Anatomical considerations}

The nasal cavity consists of two equal chambers (left and right), separated by the nasal septum, each of which has a vestibule (entrance of the nasal cavity) and main cavity. The nasal vestibule carries no cilia and is covered by stratified squamous epithelia [159]. The nasal vestibules' blood perfusion is reduced compared to the main cavity, which results in insignificant drug absorption. The nasal sinuses can pose another potential area for drug absorption, but they are considered hard to reach due to their anatomical features (located into deeper and upper parts of nasal cavity with narrow passages and complex geometry) in both humans and dogs [90, 159163]. The main nasal cavity consists of the respiratory and olfactory areas and is covered by highly vascularised mucus membranes, a fact that favours absorption into the systemic circulation. The respiratory region, in particular, consists of highly convoluted turbinates (conchae) and microvilli [164] that provide large surface-to-volume ratio and, hence, can benefit rapid drug absorption into the blood vessels.

\section{Physiological considerations}

When compared to other administration routes, IN is the only route that can enter the brain via both the blood circulation (indirect pathway) and specific nerves (direct or nose-brain pathway), circumventing the $\mathrm{BBB}$ $[90,108,158]$, as illustrated in Figs. 3 and 4.

Indirect nasal-brain drug delivery The indirect pathway involves, firstly, a rapid drug absorption by the relatively large and highly-vascularised nasal epithelium and, secondly, delivery of the drug to the brain via the systemic circulation [90]. The less lipophilicity and higher molecular weight a drug exhibits, the less is absorbed by the nasal mucosa $[109,165,166]$. Lipophilic drugs with molecular weight $<1000 \mathrm{Da}$ can be absorbed, but drugs with $<200$ Da manifest the highest absorption [109, 165, 166]. Drugs are not subject to first-pass (presystemic) hepatic metabolism after absorption [90, 108, 158]. However, following absorption to the systemic circulation, IN drugs, similar to drugs administered via other routes, are subject to the systemic hepatic metabolism, renal function and plasma proteases, and they have to

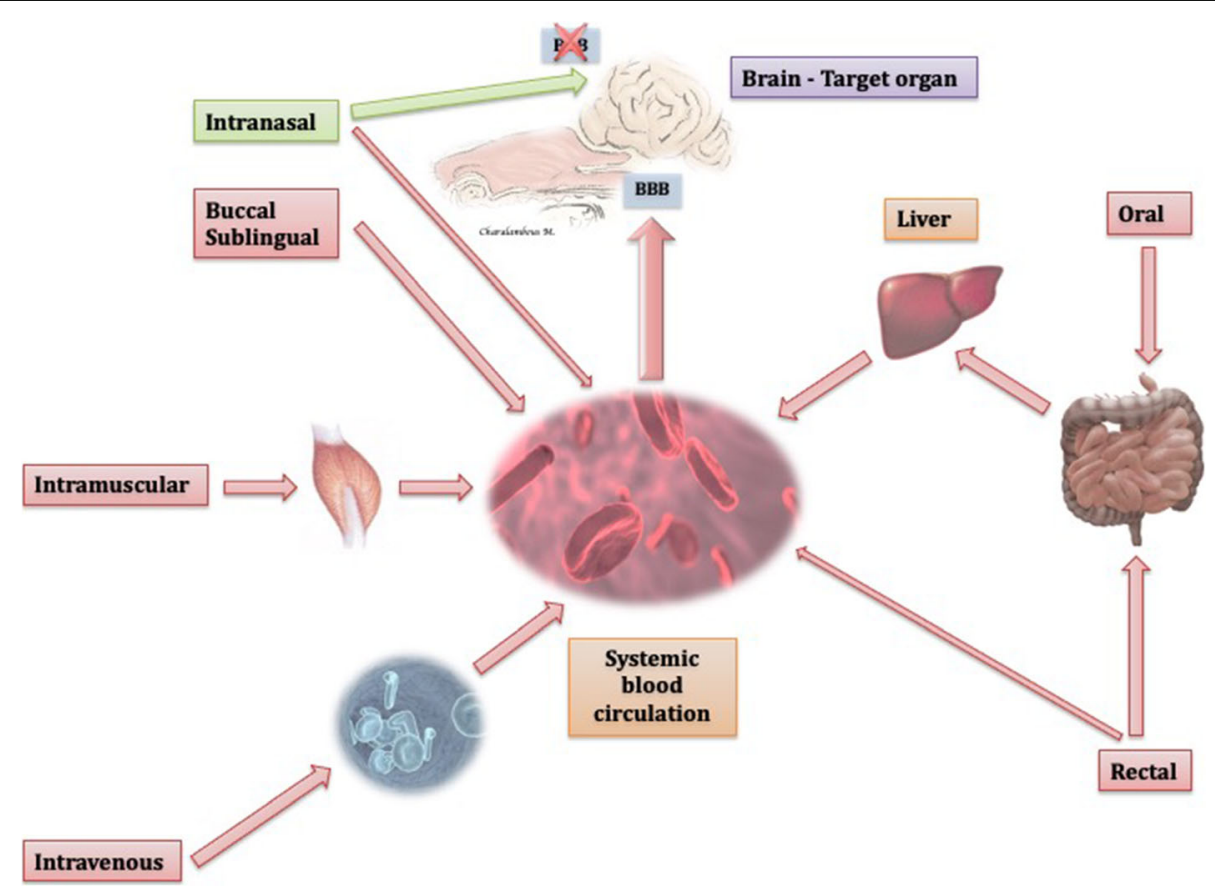

Fig. 3 Schematic illustration of the different routes of drug administration' pathways to the brain. The intranasal route is the only route that provides a direct pathway to the brain avoing the BBB (green arrow), along with an indirect pathway (red arrow). The remaining routes reach the brain indirectly (red arrows) via the systemic blood circulation passing via the BBB. Oral, in particular, and rectal route undergo first-pass hepatic metabolism, although rectally administered drugs could potentially avoid the first-pass metabolism, if they do not reach more cranial parts of the colon. Figures from authors' personal record modified with microsoft power point 


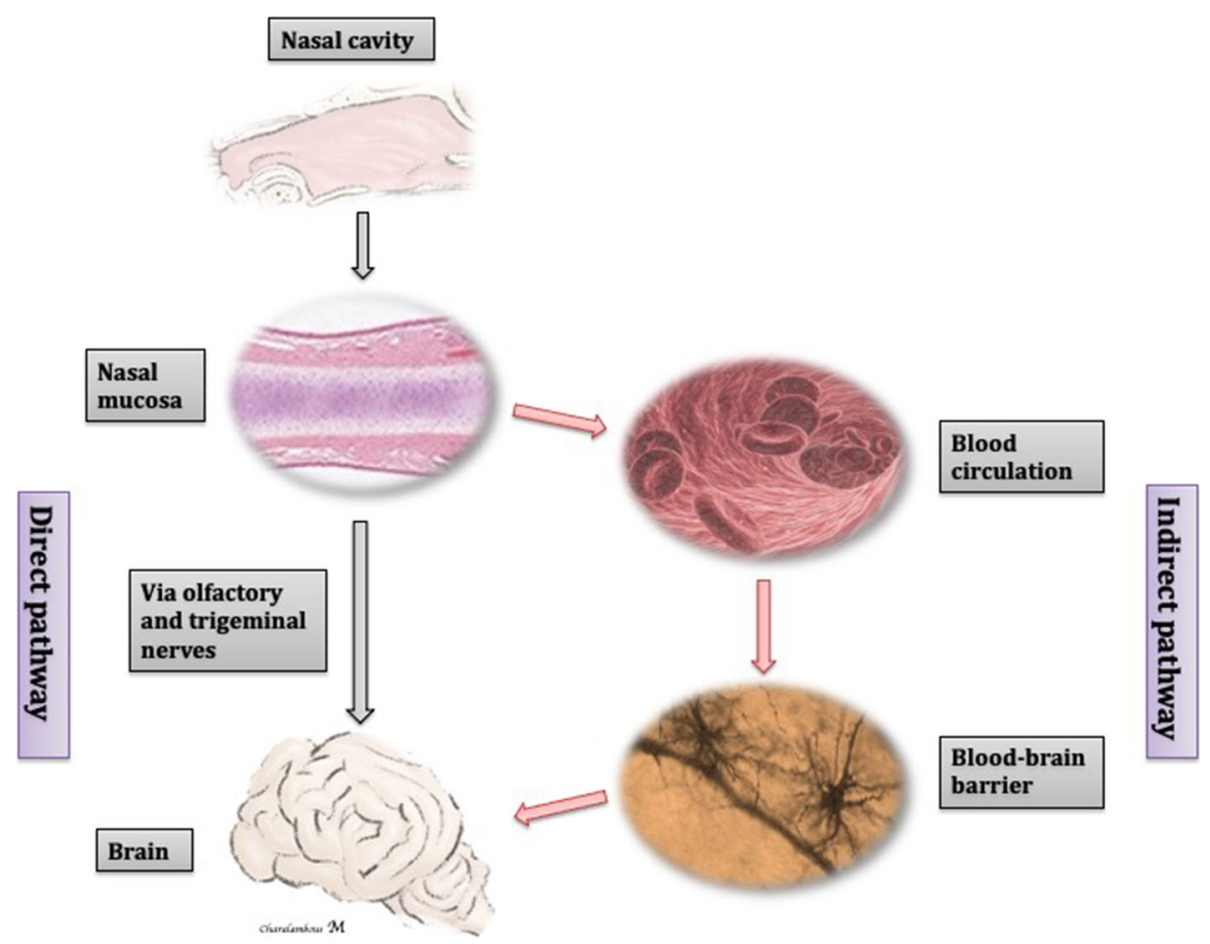

Fig. 4 Schematic illustration of the indirect and direct (nose-brain) nasal drug delivery pathways. Drugs administered IN can penetrate directly into the brain through the olfactory and/or trigeminal nerve pathways or indirectly following absorption into the systemic blood circulation. Figures from authors' personal record modified with microsoft power point

transverse the BBB for reaching the brain $[90,109,167]$. The BBB functions as a barrier, i.e., physical (intercellular tight junctions between endothelial cells and astrocyte end-feet), transport (multidrug transporters such as PGP), metabolic or enzymatic as well as immunological (perivascular mast cells, microglia and macrophages) $[168,169]$. The physical barrier prevents molecules that are hydrophilic and/or have a high molecular weight (> $400-600 \mathrm{Da}$ ) to enter the brain [170]. Interestingly, more than $98 \%$ of the drugs cannot cross the BBB freely [171174]. Modern drugs that target the brain are chemically modified to increase their stability and degree of BBB penetration [175]. BZDs are lipophilic drugs with molecular weight $<400 \mathrm{Da}$; therefore, not only can they be absorbed by the nasal mucosa to the systemic blood circulation, but the drugs can also penetrate the BBB and reach the brain $[90,166,176]$.

Direct nasal-brain drug delivery The direct pathway has gained attention in recent years as it offers a direct nose-brain axis for drug delivery via specific cranial nerves [164, 177-183]. Specifically, drugs gain access to the brain via the olfactory (nerve travels via the cribriform plate to provide special visceral afferent innervation to the olfactory mucosal epithelium) and trigeminal nerve (ophthalmic and maxillary branches travel via the cribriform plate to provide somatic afferent innervation to the respiratory mucosal epithelium) $[178,181,184-186]$. This nose-brain pathway is likely more advantageous for molecules that cannot enter the brain via other routes, as a result of their low systemic bioavailability (e.g. due to inadequate absorption into the systemic circulation or extensive metabolism and elimination) or inability to penetrate the BBB (e.g. hydrophilic or drugs with molecular weight $>400-600 \mathrm{Da}$ ) [90, 170]. There is accumulating evidence of IN administration of various hydrophilic and/or high molecular-weight molecules that reached rapid concentrations in the brain exceeding those that obtained after IV administration [158, 187, 188]; a fact that supports further the direct nose-to-brain pathway. In a study, it has been demonstrated that IN administration of drugs might lead to a drug CSF concentration that exceeds the blood plasma concentration [189-191] and can be identical to the direct intracerebroventricular administration [174]. In the olfactory region, in particular, there might be a possibility of another direct pathway, which could also contribute to the nose-brain pathway [173, 192, 193]. Specifically, the submucosal zone of the olfactory region is adjacent to the CSF flow paths of the olfactory bulb. Therefore, the IN drug could reach the 
CSF through the nasal epithelium and meninges that separate the submucosal space from the CSF [192].

Drugs following the direct pathway are transported via the nerves by various mechanisms including a) extracellular diffusion of the drug along the axonal myelin sheath and endoneurium of the nerves, b) extracellular convection of the drug following the fluid bulk flow through the perivascular zones of vessels that travel across the distal parts of the nerves and c) intracellular transport through the neuronal axons $[185,194,195]$. The extracellular convection of the drug (bulk flow) was suggested as the main mechanism of these nerve pathways, in particular for the olfactory nerve, that can be quick enough to cause the desired effect [182, 185, 195]. Final distribution of the drug from the point of entry into the brain, i.e. the olfactory bulb (drug entering through the nasal epithelium and olfactory nerve) and the brainstem (drugs entering through the trigeminal nerve), to other brain regions is likely performed via various transport mechanisms; these include intracellular (drug uptake and transfer via further connective neurons) and extracellular (drug distribution and transfer by convective bulk flow transport through the brain perivascular spaces or drug diffusion from the perivascular spaces into the brain parenchyma) [196-199].

Direct versus indirect pathway predominance in each nasal region In humans, the respiratory and olfactory regions account for $>80-90 \%$ [164] and approximately $3-8 \%[164,200]$ of the total nasal surface, respectively. The respiratory epithelium is considered more vascularised than the olfactory epithelium because one of its roles is to warm and humidify the inhaled air [201]. Therefore, the indirect pathway is likely favoured at the respiratory area, causing less amount of drug to become available for the direct (trigeminal nerve) pathway. In contrast, the olfactory area does not offer adequate highly vascularised surface $[164,200,201]$ for the indirect pathway to occur and, thus, the direct (olfactory nerve) pathway is favoured. It might be possible that, due to the above anatomical reasons, trigeminal nerve might not be as significant as the olfactory nerve for transporting drugs into the human brain [90, 202]. On contrary, in dogs $[162,201]$ and rats [203], the respiratory and olfactory regions have almost equal distribution on the overall nasal cavity. Based on the fact that animals have remarkable larger olfactory area compared to humans $[109,162,164,203]$, it might be likely that there is similar drug distribution between direct and indirect methods of drug transport in each nasal area, although this assumption has not been proven yet.

\section{Intranasal drug administration and pharmaco-resistance}

A vital future consideration is a potential connection between IN route and pharmaco-resistance. As described earlier in the text, IN delivery of drugs may follow the direct or nose-brain pathway to enter the brain avoiding BBB vascular transporters, such as PGP. This can be quite advantageous for dogs with pharmaco-resistance, where there is impaired transfer of antiseizure drugs through the $\mathrm{BBB}$ due to overexpression of these transporters $[48,204,205]$. Therefore, it would be quite interesting to conduct future studies to assess the effect of IN delivery of various antiseizure drugs specifically in dogs with pharmaco-resistant epilepsy or refractory stages of SE.

\section{Intranasal drug administration potential challenges Anatomical and physiological challenges of the nasal administration route}

Even though IN route is promising for drug delivery into the brain, it can pose important challenges regarding drug absorption. First, hydrolytic enzymes (e.g. cytochrome P450 isoenzymes and aminopeptidases) are excreted by the nasal mucosa and can metabolise nasally administered drugs reducing their local or systemic bioavailability [200, 206]. Second, the mucociliary clearance (i.e. elimination of nasally entering substances by nasal mucosa) regulates the contact time of drugs with the nasal mucosa affecting the degree of their absorption [207]. Coadministration of mucoadhesion-enhancing agents could improve drugs' contact time and absorption [90]. Third, there are epithelial transporters in nasal epithelium that can cause efflux of drugs from cells and reduce their absorption [200, 208-212]. Fourth, constriction or dilation of the nasal mucosa vessels can influence blood flow and, hence, drug absorption. Co-administering vasoconstriction agents (e.g. ephedrine or phenylephrine) can decrease drug nasal absorption [200, 213], while vasodilator agents (e.g. hydralazine) can enhance absorption [214, 215]. Fifth, nasal blood flow and drug absorption can be influenced by environmental factors such as nasal pathology, humidity, temperature, fear and stress [159, 216]. Lastly, the distribution of the IN drug can be potentially affected by anatomical features of specific canine breeds [217]. Precisely, in brachycephalic dogs, the conchae are hypertrophic, and the overall nasal cavity surface is decreased compared to dolichocephalic breeds [218, 219]; facts that could potentially limit the absorption and volume of nasally administered drugs. However, in two canine clinical studies [22, 23], various small, medium, and large breed as well as brachycephalic and dolichocephalic dogs were included, but no difference in the efficacy of IN-MDZ 


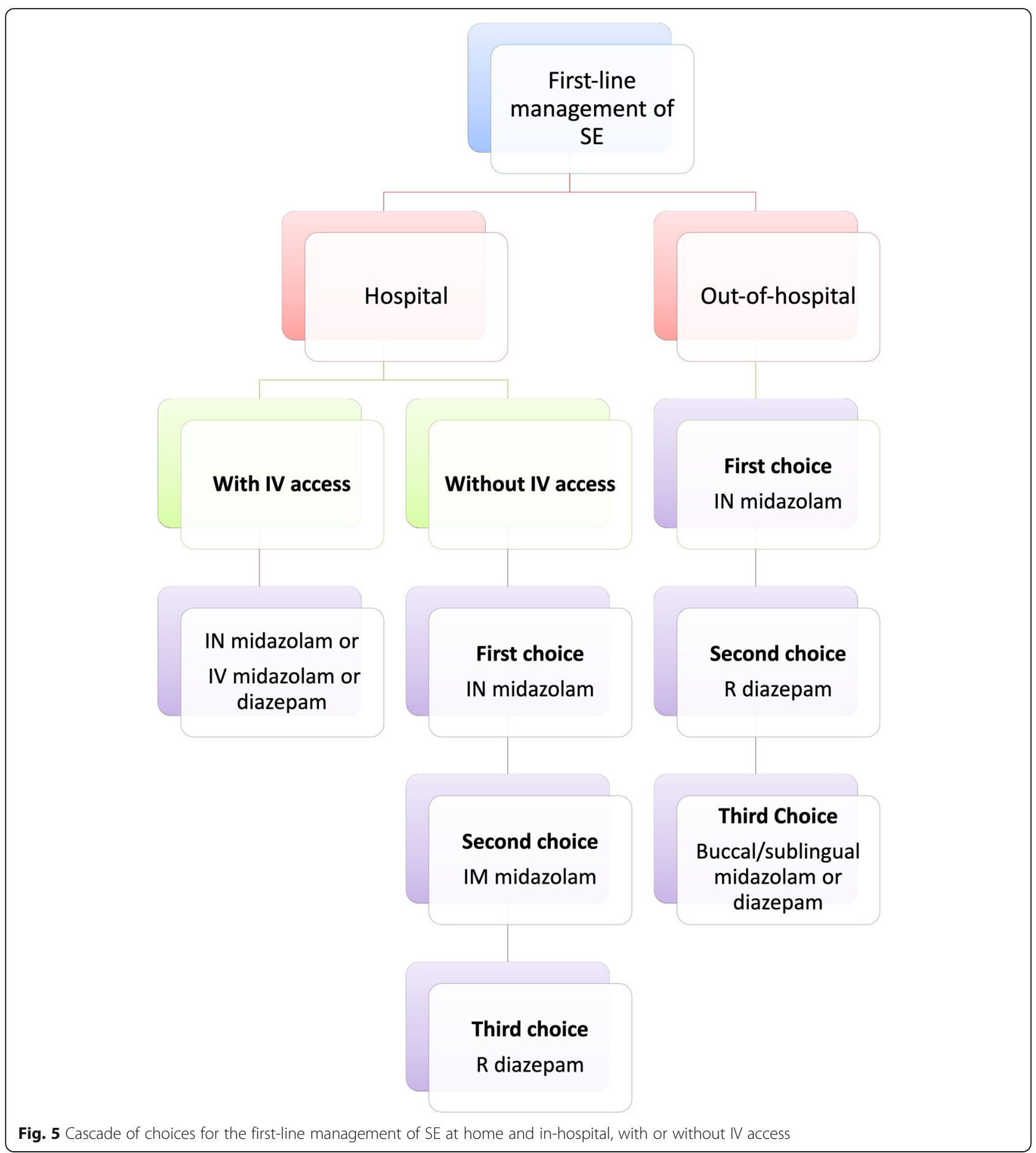

was detected among the dogs. Difficulties in applying the IN mucosal atomization device (MAD; nasal drug delivery device for MDZ) during SE were reported in $<24 \%$ of dogs $[22,23]$ and these were related to the initial unfamiliarity of personnel with the IN drug administration. Establishing IV access by placing an IV catheter [23] or using a syringe for $\mathrm{R}$ administration was perceived more difficult [22] during SE in dogs than applying the MAD at the entrance of the nasal cavity.

An ideal drug for IN administration should be characterised by adequate mucus solubility, ability for fast absorption, and rapid onset of action; highly concentrated solutions with small administration volume are also important because excess drug volume can flow out of the nasal cavity or drain into the oesophagus 
[59]. Combined with the above drug characteristics, attention should be given to the delivery device and the head position during administration as these factors can also affect drug's distribution within the nasal cavity [220, 221]. Pump sprays are widely used in human medicine nowadays to deliver between 25 and $200 \mu \mathrm{L}$ of drug volume per spray and they are relatively convenient and easy to use while allowing accurate dosage [222, 223]. Nasal drops [222] might be distributed over a larger area, although they might be cleared faster in comparison to sprays [224]. An essential limitation of both spray and, in particular, nasal drop systems is that they might require specific head positioning for correct administration, which can influence the drug's distribution within the nasal cavity, absorption and therefore efficacy [222, 223]. In veterinary medicine, the IN drug delivery method has not yet well implemented or widely explored and there are no nasal devices specifically designed for dogs. In the two veterinary clinical trials evaluating the effect of IN-MDZ in dogs with SE [22, 23], a human device (i.e. MAD) was used for IN delivery and the majority of the dogs (70-76\%) successfully responded. MAD functions like a syringe with a soft conical plug attached on it that converts the drug solution into an atomised mist. However, this device does not provide MDZ formulation already included in the device, requires time for preparation and drug administration and is not specifically adapted for the anatomical features of dogs. This can be problematic for small or brachycephalic breeds in which the correct application of the current human nasal devices might be challenging or even impossible. Dogs with SE may benefit from the design of a specific nasal device which would be adapted for small animals (e.g. thinner and more elongated device tip to adequately enter the nasal cavity and administer the drug into the whole nasal cavity) and contain drug solution ready for dosing and administration. Such a device might provide rapid and convenient delivery as well as enhanced efficacy of MDZ in dogs with SE.

\section{Conclusions}

BDZs represent the first-line and widely-used treatment choice and still remain crucial for management of canine $\mathrm{SE}$, despite their potential decline in effectiveness with more advanced SE stages. Multi-drug therapy, including drugs with different mechanisms of action, are also essential for a successful treatment. Evidence in dogs shows that efficacy and safety of non-IV routes of administration may be equal or even more effective to IV routes. This is more profound when the time to establish an IV catheter is considered. For at-home SE management, IN-MDZ is likely an effective and safe first-choice for terminating SE and well supported by clinical studies compared to other non-IV routes of administration. RDZP is unlikely to be as effective as IN-MDZ to terminate SE, based on the current evidence. IM and buccal/ sublingual administration routes might also be effective but there is currently insufficient to no clinical evidence supporting their efficacy and safety in canine SE, while their application at home by owners might be problematic. Regarding the in-hospital SE management, both IVand IN-MDZ can be successful first choices but INMDZ can be advantageous particularly when IV access has not yet been established. Overall, based on the current evidence, IN-MDZ is recommended as a firstchoice treatment in dogs with SE at home or in hospital and a proposed cascade is provided by the authors (Fig. 5). The IN pathway of drug delivery for SE provides several advantages as an administration method because it i) likely circumvents practical and efficacy-related issues associated with other IV and non-IV routes, ii) provides non-invasive and ease of administration, iv) offers capability for direct drug delivery into the brain, and $v$ ) provides enhanced drug bioavailability due to the high vascularisation of the nasal tissue, large surface available for drug absorption and avoidance of first-pass hepatic metabolism. Olfactory and trigeminal pathways might provide further advantages such as i) increased drug efficacy at lower dosages, ii) decreased risk for systemic adverse effects and iii) circumvention of $\mathrm{BBB}$; the latter can be quite beneficial in pharmaco-resistant cases. These pathways are the only channels through which the brain is somewhat directly bridged to the external environment making the nose an effective "window to the brain". A better understanding of the nasal anatomy and its limitations as well as formulation strategies can result in improved characteristics and efficacy of IN drugs.

\section{Abbreviations}

BBB: Blood-brain barrier; BZD(s): Benzodiazepines; CNS: Cental nervous system; CRI: Constant rate infusion; CSF: Cerebrospinal fluid; DZP: Diazepam; GABA: Gabapentine; IE: Idioapthic epilepsy; IM: Intramuscular; IN: Intranasal; IV: Intravenous; LZP: Lorazepam; MDZ: Midazolam; NMDA: N-methyl-daspartate; PGP: P-glycoprotein; R: Rectal; SE: Status epilepticus

\section{Acknowledgements}

Not applicable.

\section{Authors' contributions}

$M C$ contributed to the conception of the review and drafting of the manuscript. MC, HV, LVH and SB contributed to the manuscript revision. The authors read and approved the final manuscript.

\section{Funding}

Not applicable.

Availability of data and materials

Not applicable.

Ethics approval and consent to participate Not applicable. 


\section{Consent for publication}

Not applicable.

\section{Competing interests}

$\mathrm{HV}$ is a member of the editorial board of the journal.

\section{Author details}

'Small Animal Department, Faculty of Veterinary Medicine, Ghent University, 9820 Merelbeke, Belgium. ${ }^{2}$ Department of Small Animal Medicine and Surgery, University of Veterinary Medicine Hannover, 30559 Hannover, Germany.

\section{Received: 28 October 2020 Accepted: 16 February 2021 \\ Published online: 04 March 2021}

\section{References}

1. Berendt M, Farquhar RG, Mandigers PJ, Pakozdy A, Bhatti SF, De Risio L, et al. International veterinary epilepsy task force consensus report on epilepsy definition, classification and terminology in companion animals. BMC Vet Res. 2015;11:182.

2. Trinka E, Brigo F, Shorvon S. Recent advances in status epilepticus. Curr Opin Neurol. 2016;29(2):189-98.

3. Walker M. Status epilepticus: an evidence based quide. BMJ. 2005;331(7518): 673-7.

4. Lado FA, Moshe SL. How do seizures stop? Epilepsia. 2008:49(10):1651-64.

5. Blades Golubovic S, Rossmeisl JH Jr. Status epilepticus in dogs and cats, part 1: etiopathogenesis, epidemiology, and diagnosis. J Vet Emerg Crit Care (San Antonio). 2017;27(3):278-87.

6. Walker MC. Pathophysiology of status epilepticus. Neurosci Lett. 2018;667: 84-91.

7. Janigro D, Iffland PH 2nd, Marchi N, Granata T. A role for inflammation in status epilepticus is revealed by a review of current therapeutic approaches. Epilepsia. 2013;54(Suppl 6):30-2

8. Liu HT, Mazarati AM, Katsumori H, Sankar R, Waterlain CG. Substance P is expressed in hippocampal principal neurons during status epilepticus and plays a critical role in the maintenance of status epilepticus. P Natl Acad Sci USA. 1999;96(9):5286-91.

9. Kostic D, Carlson R, Henke D, Rohn K, Tipold A. Evaluation of IL-1 beta levels in epilepsy and traumatic brain injury in dogs. BMC Neurosci. 2019;20(1):29.

10. Segers E, Martle V, Piepers S, Van Ham L, Bhatti SFM. Serum C-reactive protein concentrations in dogs with idiopathic epilepsy. Vlaams Diergen Tijds. 2017;86(2):79-83.

11. Hanael E, Veksler R, Friedman A, Bar-Klein G, Senatorov W Jr, Kaufer D, et al. Blood-brain barrier dysfunction in canine epileptic seizures detected by dynamic contrast-enhanced magnetic resonance imaging. Epilepsia. 2019; 60(5):1005-16

12. Bateman SW, Parent JM. Clinical findings, treatment, and outcome of dogs with status epilepticus or cluster seizures: 156 cases (1990-1995). J Am Vet Med Assoc. 1999;215(10):1463-8.

13. Platt SR, Haag M. Canine status epilepticus: a retrospective study of 50 cases. J Small Anim Pract. 2002;43(4):151-3.

14. Saito M, Munana KR, Sharp NJ, Olby NJ. Risk factors for development of status epilepticus in dogs with idiopathic epilepsy and effects of status epilepticus on outcome and survival time: 32 cases (1990-1996). J Am Vet Med Assoc. 2001;219(5):618-23.

15. Knowles K. Idiopathic epilepsy. Clin Tech Small Anim Pract. 1998;13(3):14451.

16. Zimmermann R, Hulsmeyer V, Sauter-Louis C, Fischer A. Status epilepticus and epileptic seizures in dogs. J Vet Intern Med. 2009;23(5):970-6.

17. Costello DJ, Cole AJ. Treatment of acute seizures and status epilepticus. J Intensive Care Med. 2007;22(6):319-47.

18. Koestner A. Neuropathology of canine epilepsy. Probl Vet Med. 1989;1(4): $516-34$

19. Lothman E. The biochemical basis and pathophysiology of status epilepticus. Neurology. 1990;40(5 Suppl 2):13-23.

20. Shorvon S, Ferlisi M. The treatment of super-refractory status epilepticus: a critical review of available therapies and a clinical treatment protocol. Brain. 2011;134(Pt 10):2802-18

21. Watson C. Status epilepticus. Clinical features, pathophysiology, and treatment. West J Med. 1991;155(6):626-31.
22. Charalambous M, Bhatti SFM, Van Ham L, Platt S, Jeffery ND, Tipold A, et al. Intranasal midazolam versus rectal diazepam for the Management of Canine Status Epilepticus: a multicenter randomized parallel-group clinical trial. J Vet Intern Med. 2017;31(4):1149-58.

23. Charalambous M, Volk HA, Tipold A, Erath J, Huenerfauth E, Gallucci A, et al. Comparison of intranasal versus intravenous midazolam for management of status epilepticus in dogs: a multi-center randomized parallel group clinical study. J Vet Intern Med. 2019;33(6):2709-17.

24. De Waele L, Boon P, Ceulemans B, Dan B, Jansen A, Legros B, et al. First line management of prolonged convulsive seizures in children and adults: good practice points. Acta Neurol Belg. 2013;113(4):375-80.

25. Patterson EN. Status epilepticus and cluster seizures. Vet Clin North Am Small Anim Pract. 2014:44(6):1103-12.

26. Nair PP, Kalita J, Misra UK. Status epilepticus: why, what, and how. J Postgrad Med. 2011:57(3):242-52.

27. Falco-Walter JJ, Bleck T. Treatment of Established Status Epilepticus. J Clin Med. 2016:5.

28. Gollwitzer $\mathrm{S}$, Hamer HM. The treatment and prognosis of refractory and super-refractory status Epilepticus. Aktuel Neurol. 2017:44(9):662-8.

29. Podell M, Fenner WR, Powers JD. Seizure classification in dogs from a nonreferral-based population. J Am Vet Med Assoc. 1995;206(11):1721-8.

30. Tesoro EP, Brophy GM. Pharmacological management of seizures and status epilepticus in critically ill patients. J Pharm Pract. 2010;23(5):441-54.

31. Zaccara G, Giannasi G, Oggioni R, Rosati E, Tramacere L, Palumbo P, et al. Challenges in the treatment of convulsive status epilepticus. Seizure. 2017; 47:17-24

32. Naylor DE, Liu H, Wasterlain CG. Trafficking of GABA(a) receptors, loss of inhibition, and a mechanism for pharmacoresistance in status epilepticus. J Neurosci. 2005;25(34):7724-33.

33. Platt SR, Randell SC, Scott KC, Chrisman CL, Hill RC, Gronwall RR. Comparison of plasma benzodiazepine concentrations following intranasal and intravenous administration of diazepam to dogs. Am J Vet Res. 2000; 61(6):651-4

34. Niquet J, Baldwin R, Suchomelova L, Lumley L, Naylor D, Eavey R, et al. Benzodiazepine-refractory status epilepticus: pathophysiology and principles of treatment. Ann N Y Acad Sci. 2016;1378(1):166-73.

35. Deeb TZ, Maguire J, Moss SJ. Possible alterations in GABAA receptor signaling that underlie benzodiazepine-resistant seizures. Epilepsia. 2012 53(Suppl 9):79-88.

36. Holtkamp M, Tong X, Walker MC. Propofol in subanesthetic doses terminates status epilepticus in a rodent model. Ann Neurol. 2001;49(2): 260-3.

37. Orser BA, Canning KJ, Macdonald JF. Mechanisms of general anesthesia. Curr Opin Anaesthesiol. 2002;15(4):427-33.

38. Rogawski MA, Loya CM, Reddy K, Zolkowska D, Lossin C. Neuroactive steroids for the treatment of status epilepticus. Epilepsia. 2013;54(Suppl 6): 93-8.

39. Silayeva L, Deeb TZ, Hines RM, Kelley MR, Munoz MB, Lee HH, et al. KCC2 activity is critical in limiting the onset and severity of status epilepticus. Proc Natl Acad Sci U S A. 2015;112(11):3523-8.

40. Naylor DE, Liu H, Niquet J, Wasterlain CG. Rapid surface accumulation of NMDA receptors increases glutamatergic excitation during status epilepticus. Neurobiol Dis. 2013:54:225-38.

41. Rajasekaran K, Todorovic M, Kapur J. Calcium-permeable AMPA receptors are expressed in a rodent model of status epilepticus. Ann Neurol. 2012. 72(1):91-102.

42. Eckel R, Szulc B, Walker MC, Kittler JT. Activation of calcineurin underlies altered trafficking of alpha2 subunit containing GABAA receptors during prolonged epileptiform activity. Neuropharmacology. 2015;88:82-90.

43. Joshi S, Rajasekaran K, Hawk KM, Brar J, Ross BM, Tran CA, et al. Phosphatase inhibition prevents the activity-dependent trafficking of GABAA receptors during status epilepticus in the young animal. Epilepsia. 2015;56(9):1355-65.

44. Martin BS, Kapur J. A combination of ketamine and diazepam synergistically controls refractory status epilepticus induced by cholinergic stimulation. Epilepsia. 2008;49(2):248-55.

45. Rice AC, DeLorenzo RJ. N-methyl-D-aspartate receptor activation regulates refractoriness of status epilepticus to diazepam. Neuroscience. 1999;93(1): $117-23$.

46. Walton NY, Treiman DM. Motor and electroencephalographic response of refractory experimental status epilepticus in rats to treatment with MK-801, diazepam, or MK-801 plus diazepam. Brain Res. 1991;553(1):97-104. 
47. Volk HA, Loscher W. Multidrug resistance in epilepsy: rats with drug-resistant seizures exhibit enhanced brain expression of P-glycoprotein compared with rats with drug-responsive seizures. Brain. 2005;128(Pt 6):1358-68.

48. Pekcec A, Unkruer B, Stein V, Bankstahl JP, Soerensen J, Tipold A, et al. Overexpression of P-glycoprotein in the canine brain following spontaneous status epilepticus. Epilepsy Res. 2009;83(2-3):144-51.

49. Sisodiya SM, Thom M. Widespread upregulation of drug-resistance proteins in fatal human status epilepticus. Epilepsia. 2003;44(2):261-4.

50. Zhang L, Ong WY, Lee T. Induction of P-glycoprotein expression in astrocytes following intracerebroventricular kainate injections. Exp Brain Res. 1999;126(4):509-16.

51. Wagner SO, Sams RA, Podell M. Chronic phenobarbital therapy reduces plasma benzodiazepine concentrations after intravenous and rectal administration of diazepam in the dog. J Vet Pharmacol Ther. 1998;21(5): 335-41.

52. Mealey $\mathrm{KL}$, Boothe DM. Bioavailability of benzodiazepines following rectal administration of diazepam in dogs. J Vet Pharmacol Ther. 1995;18(1):72-4.

53. Papich MG, Alcorn J. Absorption of diazepam after its rectal administration in dogs. Am J Vet Res. 1995;56(12):1629-36.

54. Wermeling DP, Record KA, Archer SM, Rudy AC. A pharmacokinetic and pharmacodynamic study, in healthy volunteers, of a rapidly absorbed intranasal midazolam formulation. Epilepsy Res. 2009:83(2-3):124-32.

55. Horikawa H, Tada T, Sakai M, Karube T, Ichiyanagi K. Effects of midazolam on the threshold of lidocaine-induced seizures in the dog--comparison with diazepam. J Anesth. 1990;4(3):265-9

56. Buhrer M, Maitre PO, Crevoisier C, Stanski DR. Electroencephalographic effects of benzodiazepines. II. Pharmacodynamic modeling of the electroencephalographic effects of midazolam and diazepam. Clin Pharmacol Ther. 1990;48(5):555-67.

57. Rossetti AO. Treatment options in the management of status epilepticus. Curr Treat Options Neurol. 2010;12(2):100-12.

58. Winsnes M, Jeppsson R, Sjoberg B. Diazepam adsorption to infusion sets and plastic syringes. Acta Anaesthesiol Scand. 1981;25(2):93-6.

59. Walker MC, Tong X, Brown S, Shorvon SD, Patsalos PN. Comparison of single- and repeated-dose pharmacokinetics of diazepam. Epilepsia. 1998; 39(3):283-9.

60. Mazarati AM, Baldwin R, Klitgaard H, Matagne A, Wasterlain CG. Anticonvulsant effects of levetiracetam and levetiracetam-diazepam combinations in experimental status epilepticus. Epilepsy Res. 2004;58(2-3):167-74.

61. Uges JW, van Huizen MD, Engelsman J, Wilms EB, Touw DJ, Peeters E, et al. Safety and pharmacokinetics of intravenous levetiracetam infusion as addon in status epilepticus. Epilepsia. 2009;50(3):415-21.

62. Lowenstein DH, Cloyd J. Out-of-hospital treatment of status epilepticus and prolonged seizures. Epilepsia. 2007;48(Suppl 8):96-8.

63. Leppik IE, Derivan AT, Homan RW, Walker J, Ramsay RE, Patrick B. Doubleblind study of lorazepam and diazepam in status epilepticus. JAMA. 1983; 249(11):1452-4

64. Silbergleit R, Durkalski $V$, Lowenstein D, Conwit R, Pancioli A, Palesch $Y$, et al. Intramuscular versus intravenous therapy for prehospital status epilepticus. N Engl J Med. 2012;366(7):591-600

65. Treiman DM, Meyers PD, Walton NY, Collins JF, Colling C, Rowan AJ, et al. A comparison of four treatments for generalized convulsive status epilepticus. Veterans affairs status Epilepticus cooperative study group. N Engl J Med. 1998;339(12):792-8.

66. Welch RD, Nicholas K, Durkalski-Mauldin VL, Lowenstein DH, Conwit R, Mahajan PV, et al. Intramuscular midazolam versus intravenous lorazepam for the prehospital treatment of status epilepticus in the pediatric population. Epilepsia. 2015;56(2):254-62.

67. Brophy GM, Bell R, Claassen J, Alldredge B, Bleck TP, Glauser T, et al. Guidelines for the evaluation and management of status epilepticus. Neurocrit Care. 2012;17(1):3-23.

68. Alldredge BK, Gelb AM, Isaacs SM, Corry MD, Allen F, Ulrich S, et al. A comparison of lorazepam, diazepam, and placebo for the treatment of outof-hospital status epilepticus. N Engl J Med. 2001;345(9):631-7.

69. Brigo F, Bragazzi NL, Bacigaluppi S, Nardone R, Trinka E. Is intravenous lorazepam really more effective and safe than intravenous diazepam as first-line treatment for convulsive status epilepticus? A systematic review with meta-analysis of randomized controlled trials. Epilepsy Behav. 2016;64(Pt A):29-36.

70. McTague A, Martland T, Appleton R. Drug management for acute tonicclonic convulsions including convulsive status epilepticus in children. Cochrane Database Syst Rev. 2018;1:CD001905.
71. Wu W, Zhang L, Xue R. Lorazepam or diazepam for convulsive status epilepticus: a meta-analysis. J Clin Neurosci. 2016:29:133-8.

72. Schwartz M, Munana KR, Nettifee-Osborne JA, Messenger KM, Papich MG. The pharmacokinetics of midazolam after intravenous, intramuscular, and rectal administration in healthy dogs. J Vet Pharmacol Ther. 2013;36(5):471-7.

73. Court MH, Greenblatt DJ. Pharmacokinetics and preliminary observations of behavioral changes following administration of midazolam to dogs. J Vet Pharmacol Ther. 1992;15(4):343-50.

74. Brown SA, Jacobson JD, Hartsfield SM. Pharmacokinetics of midazolam administered concurrently with ketamine after intravenous bolus or infusion in dogs. J Vet Pharmacol Ther. 1993;16(4):419-25.

75. Meierkord H, Boon P, Engelsen B, Gocke K, Shorvon S, Tinuper P, et al. EFNS guideline on the management of status epilepticus. Eur J Neurol. 2006;13(5): 445-50.

76. Meierkord H, Boon P, Engelsen B, Gocke K, Shorvon S, Tinuper P, et al. EFNS guideline on the management of status epilepticus in adults. Eur J Neurol. 2010;17(3):348-55

77. Glauser T, Shinnar S, Gloss D, Alldredge B, Arya R, Bainbridge J, et al Evidence-based guideline: treatment of convulsive status Epilepticus in children and adults: report of the guideline Committee of the American Epilepsy Society. Epilepsy Cur. 2016;16(1):48-61.

78. Thomas WB. Idiopathic epilepsy in dogs and cats. Vet Clin North Am Small Anim Pract. 2010;40(1):161-79.

79. Alshehri A, Abulaban A, Bokhari R, Kojan S, Alsalamah M, Ferwana M, et al. Intravenous versus nonintravenous benzodiazepines for the cessation of seizures: a systematic review and meta-analysis of randomized controlled trials. Acad Emerg Med. 2017;24:875-83.

80. Manno EM. Status epilepticus: current treatment strategies. Neurohospitalist. 2011:1(1):23-31.

81. Marawar R, Basha M, Mahulikar A, Desai A, Suchdev K, Shah A. Updates in refractory status Epilepticus. Crit Care Res Pract. 2018;2018:9768949.

82. Pang T, Hirsch LJ. Treatment of convulsive and nonconvulsive status Epilepticus. Curr Treat Options Neurol. 2005;7(4):247-59.

83. Sirven JI, Waterhouse E. Management of status epilepticus. Am Fam Physician. 2003;68(3):469-76.

84. Abou-Khalil B, Wheless J, Rogin J, Wolter KD, Pixton GC, Shukla RB, et al. A double-blind, randomized, placebo-controlled trial of a diazepam autoinjector administered by caregivers to patients with epilepsy who require intermittent intervention for acute repetitive seizures. Epilepsia. 2013;54(11): 1968-76.

85. Silbergleit R, Lowenstein D, Durkalski V, Conwit R. Neurological Emergency Treatment Trials I. RAMPART (Rapid Anticonvulsant Medication Prior to Arrival Trial): a double-blind randomized clinical trial of the efficacy of intramuscular midazolam versus intravenous lorazepam in the prehospital treatment of status epilepticus by paramedics. Epilepsia. 2011;52(Suppl 8): $45-7$

86. Chamberlain JM, Altieri MA, Futterman C, Young GM, Ochsenschlager DW Waisman Y. A prospective, randomized study comparing intramuscular midazolam with intravenous diazepam for the treatment of seizures in children. Pediatr Emerg Care. 1997;13(2):92-4.

87. Shah I, Deshmukh $C$. Intramuscular midazolam vs intravenous diazepam for acute seizures. Indian J Pediatr. 2005;72(8):667-70.

88. Riva A, lapadre G, Grasso EA, Balagura G, Striano P, Verrotti A. Intramuscular midazolam for treatment of status Epilepticus. Expert Opin Pharmacother. 2020:1-8.

89. Arya R, Kothari H, Zhang Z, Han B, Horn PS, Glauser TA. Efficacy of nonvenous medications for acute convulsive seizures: a network metaanalysis. Neurology. 2015;85(21):1859-68.

90. Kapoor M, Cloyd JC, Siegel RA. A review of intranasal formulations for the treatment of seizure emergencies. J Control Release. 2016;237:147-59.

91. Godin B, Touitou E. Transdermal skin delivery: predictions for humans from in vivo, ex vivo and animal models. Adv Drug Deliv Rev. 2007; 59(11):1152-61.

92. Nokhodchi A, Shokri J, Dashbolaghi A, Hassan-Zadeh D, Ghafourian T, Barzegar-Jalali M. The enhancement effect of surfactants on the penetration of lorazepam through rat skin. Int J Pharm. 2003;250(2):359-69.

93. Akhtar N, Singh V, Yusuf M, Khan RA. Non-invasive drug delivery technology: development and current status of transdermal drug delivery devices, techniques and biomedical applications. Biomed Tech (Berl). 2020; 65(3):243-72. 
94. Brown MB, Martin GP, Jones SA, Akomeah FK. Dermal and transdermal drug delivery systems: current and future prospects. Drug Deliv. 2006;13(3):175-87.

95. Barnes Heller HL, Trepanier LA, Robertson M, Mei C. Prospective crossover clinical trial comparing transdermal with oral phenobarbital administration in epileptic cats. J Feline Med Surg. 2019;21(12):1181-7.

96. Krull DP, Thomovsky SA, Chen AV, Mealey KL, Papich MG. Evaluation of transdermal Administration of Phenobarbital in healthy cats. J Am Anim Hosp Assoc. 2019;55(1):1-7.

97. Smith C, Barnes Heller HL, Reif N, Van Hesteren M, Reinhart JM. Serum levetiracetam concentrations after transdermal levetiracetam administration, 3 times daily, to healthy cats. J Vet Intern Med. 2019;33(2):827-30.

98. Mclntyre J, Robertson S, Norris E, Appleton R, Whitehouse WP, Phillips B, et al. Safety and efficacy of buccal midazolam versus rectal diazepam for emergency treatment of seizures in children: a randomised controlled trial. Lancet. 2005;366(9481):205-10.

99. Ashrafi MR, Khosroshahi N, Karimi P, Malamiri RA, Bavarian B, Zarch AV, et al. Efficacy and usability of buccal midazolam in controlling acute prolonged convulsive seizures in children. Eur J Paediatr Neurol. 2010;14(5):434-8.

100. Nakken KO, Lossius MI. Buccal midazolam or rectal diazepam for treatment of residential adult patients with serial seizures or status epilepticus. Acta Neurol Scand. 2011;124(2):99-103.

101. Scheepers M, Comish S, Cordes L, Clough P, Scheepers B. Buccal midazolam and rectal diazepam for epilepsy. Lancet. 1999;353(9166):1797-8.

102. Scott RC, Besag FM, Neville BG. Buccal midazolam and rectal diazepam for treatment of prolonged seizures in childhood and adolescence: a randomised trial. Lancet. 1999;353(9153):623-6.

103. Talukdar B, Chakrabarty B. Efficacy of buccal midazolam compared to intravenous diazepam in controlling convulsions in children: a randomized controlled trial. Brain and Development. 2009;31(10):744-9.

104. Kutlu NO, Dogrul M, Yakinci C, Soylu H. Buccal midazolam for treatment of prolonged seizures in children. Brain and Development. 2003;25(4):275-8.

105. Aldawsari MF, Lau WW, Babu RJ, Arnold RD, Platt SR. Pharmacokinetic evaluation of novel midazolam gel formulations following buccal administration to healthy dogs. Am J Vet Res. 2018;79(1):73-82.

106. Zhang J, Niu S, Zhang H, Streisand JB. Oral mucosal absorption of midazolam in dogs is strongly pH dependent. J Pharm Sci. 2002;91(4):980-2.

107. Spencer D. Hope for new treatments for acute repetitive seizures. Epilepsy Curr. 2014;14(3):147-9.

108. Anderson GD, Saneto RP. Current oral and non-oral routes of antiepileptic drug delivery. Adv Drug Deliv Rev. 2012;64(10):911-8.

109. Musumeci T, Bonaccorso A, Puglisi G. Epilepsy Disease and Nose-to-Brain Delivery of Polymeric Nanoparticles: An Overview. Pharmaceutics. 2019;11:3.

110. Harris D, Robinson JR. Drug delivery via the mucous membranes of the oral cavity. J Pharm Sci. 1992;81:1-10.

111. Greenblatt DJ, Divoll M, Harmatz JS, Shader RI. Pharmacokinetic comparison of sublingual lorazepam with intravenous, intramuscular, and oral lorazepam. J Pharm Sci. 1982;71(2):248-52.

112. Malu CK, Kahamba DM, Walker TD, Mukampunga C, Musalu EM, Kokolomani J, et al. Efficacy of sublingual lorazepam versus intrarectal diazepam for prolonged convulsions in sub-Saharan Africa. J Child Neurol. 2014;29(7):895-902.

113. Gavhane YN, Yadav AV. Loss of orally administered drugs in Gl tract. Saudi Pharm J. 2012;20(4):331-44.

114. Kolars JC, Lown KS, Schmiedlin-Ren P, Ghosh M, Fang C, Wrighton SA, et al. CYP3A gene expression in human gut epithelium. Pharmacogenetics. 1994; 4(5):247-59.

115. Paine MF, Shen DD, Kunze KL, Perkins JD, Marsh CL, McVicar JP, et al. Firstpass metabolism of midazolam by the human intestine. Clin Pharmacol Ther. 1996;60(1):14-24.

116. Thummel KE, OShea D, Paine MF, Shen DD, Kunze KL, Perkins JD, et al. Oral first-pass elimination of midazolam involves both gastrointestinal and hepatic CYP3A-mediated metabolism. Clin Pharmacol Ther. 1996;59(5):491502.

117. Jannin V, Lemagnen G, Gueroult P, Larrouture D, Tuleu C. Rectal route in the 21st century to treat children. Adv Drug Deliv Rev. 2014;73:34-49.

118. Dhaliwal JS, Rosani A, Saadabadi A. Diazepam. Treasure Island: StatPearls; 2020.

119. Betcher DL, Burnham N. Midazolam for outpatient sedation. J Pediatr Oncol Nurs. 1992;9(3):136-8.

120. Guittet C, Manso M, Burton I, Granier LA, Marcon F. A two-way randomized cross-over pharmacokinetic and Pharmacodynamic study of an innovative Oral solution of midazolam (ADV6209). Pharm Res. 2017;34(9):1840-8.
121. Dhillon S, Oxley J, Richens A. Bioavailability of diazepam after intravenous, oral and rectal administration in adult epileptic patients. Br J Clin Pharmacol. 1982;13(3):427-32.

122. Costa C, Moreira JN, Amaral MH, Sousa Lobo JM, Silva AC. Nose-to-brain delivery of lipid-based nanosystems for epileptic seizures and anxiety crisis. J Control Release. 2019;295:187-200.

123. Loscher W, Frey HH. Pharmacokinetics of diazepam in the dog. Arch Int Pharmacodyn Ther. 1981;254(2):180-95.

124. Crawshaw AA, Cock HR. Medical management of status epilepticus: emergency room to intensive care unit. Seizure. 2020;75:145-52.

125. Seigler RS. The administration of rectal diazepam for acute management of seizures. J Emerg Med. 1990;8(2):155-9.

126. Dieckmann RA. Rectal diazepam for prehospital pediatric status epilepticus. Ann Emerg Med. 1994;23(2):216-24.

127. Alldredge BK, Wall DB, Ferriero DM. Effect of prehospital treatment on the outcome of status epilepticus in children. Pediatr Neurol. 1995;12(3):213-6.

128. Dreifuss FE, Rosman NP, Cloyd JC, Pellock JM, Kuzniecky RI, Lo WD, et al. A comparison of rectal diazepam gel and placebo for acute repetitive seizures. N Engl J Med. 1998;338(26):1869-75.

129. Brigo F, Nardone R, Tezzon F, Trinka E. Nonintravenous midazolam versus intravenous or rectal diazepam for the treatment of early status epilepticus: a systematic review with meta-analysis. Epilepsy Behav. 2015;49:325-36.

130. Haut SR, Seinfeld S, Pellock J. Benzodiazepine use in seizure emergencies: a systematic review. Epilepsy Behav. 2016;63:109-17.

131. Probst CW, Thomas WB, Moyers TD, Martin T, Cox S. Evaluation of plasma diazepam and nordiazepam concentrations following administration of diazepam intravenously or via suppository per rectum in dogs. Am J Vet Res. 2013;74(4):611-5.

132. ORegan ME, Brown JK, Clark M. Nasal rather than rectal benzodiazepines in the management of acute childhood seizures? Dev Med Child Neurol. 1996; 38(11):1037-45.

133. Allonen H, Ziegler G, Klotz U. Midazolam kinetics. Clin Pharmacol Ther. 1981; 30(5):653-61.

134. Malinovsky JM, Lejus C, Servin F, Lepage JY, Le Normand Y, Testa S, et al. Plasma concentrations of midazolam after i.V., nasal or rectal administration in children. Br J Anaesth. 1993;70(6):617-20.

135. Rey E, Delaunay L, Pons G, Murat I, Richard MO, Saint-Maurice C, et al. Pharmacokinetics of midazolam in children: comparative study of intranasal and intravenous administration. Eur J Clin Pharmacol. 1991;41(4):355-7.

136. Lahat E, Goldman M, Barr J, Bistritzer T, Berkovitch M. Comparison of intranasal midazolam with intravenous diazepam for treating febrile seizures in children: prospective randomised study. BMJ. 2000;321(7253):83-6.

137. Mahmoudian T, Zadeh MM. Comparison of intranasal midazolam with intravenous diazepam for treating acute seizures in children. Epilepsy Behav. 2004;5(2):253-5

138. Javadzadeh $M$, Sheibani $K$, Hashemieh M, Saneifard H. Intranasal midazolam compared with intravenous diazepam in patients suffering from acute seizure: a randomized clinical trial. Iran J Pediatr. 2012;22(1):1-8.

139. Ugwoke MI, Exaud S, Van Den Mooter G, Verbeke N, Kinget R. Bioavailability of apomorphine following intranasal administration of mucoadhesive drug delivery systems in rabbits. Eur J Pharm Sci. 1999;9(2):213-9.

140. Varshosaz J, Sadrai H, Alinagari R. Nasal delivery of insulin using chitosan microspheres. J Microencapsul. 2004;21(7):761-74.

141. Varshosaz J, Sadrai H, Heidari A. Nasal delivery of insulin using bioadhesive chitosan gels. Drug Deliv. 2006;13(1):31-8.

142. Furubayashi T, Kamaguchi A, Kawaharada K, Masaoka Y, Kataoka M, Yamashita S, et al. Evaluation of the contribution of the nasal cavity and gastrointestinal tract to drug absorption following nasal application to rats. Biol Pharm Bull. 2007;30(3):608-11.

143. Leonard AK, Sileno AP, Brandt GC, Foerder CA, Quay SC, Costantino HR. In vitro formulation optimization of intranasal galantamine leading to enhanced bioavailability and reduced emetic response in vivo. Int J Pharm. 2007;335(1-2):138-46.

144. Cattet MR, Caulkett NA, Wilson C, Vandenbrink T, Brook RK. Intranasal administration of xylazine to reduce stress in elk captured by net gun. J Wildl Dis. 2004;40(3):562-5.

145. Duque JC, Oleskovicz N, Guirro EC, Valadao CA, Soares VE. Relative potency of ketamine and S(+)-ketamine in dogs. J Vet Pharmacol Ther. 2008;31(4): 344-8.

146. Gerritsmann H, Stalder GL, Seilern-Moy K, Knauer F, Walzer C. Comparison of $\mathrm{S}(+)$-ketamine and ketamine, with medetomidine, for field anaesthesia in 
the European brown hare (Lepus europaeus). Vet Anaesth Analg. 2012;39(5): 511-9.

147. Micieli F, Santangelo B, Napoleone G, Di Dona F, Mennonna G, Vesce G. Intranasal fentanyl for acute severe pain episodes control in a dog. Vet Anaesth Analg. 2017;44(6):1400-1.

148. Shury TK, Caulkett NA, Woodbury MR. Intranasal naltrexone and atipamezole for reversal of white-tailed deer immobilized with carfentanil and medetomidine. Can Vet J. 2010;51(5):501-5.

149. Weiland LC, Kluge K, Kutter APN, Kronen PW. Clinical evaluation of intranasal medetomidine-ketamine and medetomidine-S(+)-ketamine for induction of anaesthesia in rabbits in two centres with two different administration techniques. Vet Anaesth Analg. 2017;44(1):98-105.

150. Vlerick L, Devreese M, Peremans K, Dockx R, Croubels S, Duchateau L, et al. Pharmacokinetics, absolute bioavailability and tolerability of ketamine after intranasal administration to dexmedetomidine sedated dogs. PLoS One. 2020;15(1):e0227762.

151. Humphries LK, Eiland LS. Treatment of acute seizures: is intranasal midazolam a viable option? J Pediatr Pharmacol Ther. 2013;18(2):79-87.

152. Boddu SHS, Kumari S. A Short Review on the Intranasal Delivery of Diazepam for Treating Acute Repetitive Seizures. Pharmaceutics. 2020:12.

153. Ivaturi VD, Riss JR, Kriel RL, Cloyd JC. Pharmacokinetics and tolerability of intranasal diazepam and midazolam in healthy adult volunteers. Acta Neurol Scand. 2009;120(5):353-7.

154. Schrier L, Zuiker R, Merkus FW, Klaassen ES, Guan Z, Tuk B, et al. Pharmacokinetics and pharmacodynamics of a new highly concentrated intranasal midazolam formulation for conscious sedation. Br J Clin Pharmacol. 2017:83(4):721-31.

155. Eagleson JS, Platt SR, Strong DL, Kent M, Freeman AC, Nghiem PP, et al. Bioavailability of a novel midazolam gel after intranasal administration in dogs. Am J Vet Res. 2012;73(4):539-45.

156. Lui CY, Amidon GL, Goldberg A. Intranasal absorption of flurazepam, midazolam, and triazolam in dogs. J Pharm Sci. 1991;80(12):1125-9.

157. Musulin SE, Mariani CL, Papich MG. Diazepam pharmacokinetics after nasal drop and atomized nasal administration in dogs. J Vet Pharmacol Ther. 2011;34(1):17-24

158. Hong SS, Oh KT, Choi HG, Lim SJ. Liposomal Formulations for Nose-to-Brain Delivery: Recent Advances and Future Perspectives. Pharmaceutics. 2019;11:10.

159. Merkus FW, Verhoef JC, Schipper NG, Marttin E. Nasal mucociliary clearance as a factor in nasal drug delivery. Adv Drug Deliv Rev. 1998;29(1-2):13-38.

160. Agu RU. Challenges in nasal drug absorption: how far have we come? Ther Deliv. 2016;7(7):495-510.

161. Djupesland PG. Nasal drug delivery devices: characteristics and performance in a clinical perspective-a review. Drug Deliv Transl Res. 2013;3(1):42-62.

162. Craven BA, Neuberger T, Paterson EG, Webb AG, Josephson EM, Morrison $\mathrm{EE}$, et al. Reconstruction and morphometric analysis of the nasal airway of the dog (Canis familiaris) and implications regarding olfactory airflow. Anat Rec (Hoboken). 2007;290(11):1325-40.

163. Craven BA, Paterson EG, Settles GS. The fluid dynamics of canine olfaction: unique nasal airflow patterns as an explanation of macrosmia. J R Soc Interface. 2010;7(47):933-43.

164. Illum L. Nasal clearance in health and disease. J Aerosol Med. 2006:19(1):929.

165. McMartin C, Hutchinson LE, Hyde R, Peters GE. Analysis of structural requirements for the absorption of drugs and macromolecules from the nasal cavity. J Pharm Sci. 1987;76(7):535-40.

166. Ozsoy Y, Gungor S, Cevher E. Nasal delivery of high molecular weight drugs. Molecules. 2009:14(9):3754-79.

167. Kozlovskaya L, Abou-Kaoud M, Stepensky D. Quantitative analysis of drug delivery to the brain via nasal route. J Control Release. 2014;189:133-40.

168. Abbott NJ, Ronnback L, Hansson E. Astrocyte-endothelial interactions at the blood-brain barrier. Nat Rev Neurosci. 2006;7(1):41-53.

169. Pardridge WM. Molecular biology of the blood-brain barrier. Mol Biotechnol. 2005;30(1):57-70.

170. Banks WA. Characteristics of compounds that cross the blood-brain barrier. BMC Neurol. 2009;9(Suppl 1):S3.

171. Abbott NJ, Patabendige AA, Dolman DE, Yusof SR, Begley DJ. Structure and function of the blood-brain barrier. Neurobiol Dis. 2010;37(1):13-25.

172. Cardoso FL, Brites D, Brito MA. Looking at the blood-brain barrier: molecular anatomy and possible investigation approaches. Brain Res Rev. 2010;64(2):328-63.

173. Pardridge WM. Drug transport across the blood-brain barrier. J Cereb Blood Flow Metab. 2012;32(11):1959-72.
174. Merkus P, Guchelaar HJ, Bosch DA, Merkus FW. Direct access of drugs to the human brain after intranasal drug administration? Neurology. 2003;60(10): 1669-71.

175. Marianecci C, Rinaldi F, Hanieh PN, Di Marzio L, Paolino D, Carafa M. Drug delivery in overcoming the blood-brain barrier: role of nasal mucosal grafting. Drug Des Devel Ther. 2017;11:325-35.

176. Griffin CE 3rd, Kaye AM, Bueno FR, Kaye AD. Benzodiazepine pharmacology and central nervous system-mediated effects. Ochsner J. 2013;13(2):214-23.

177. Talegaonkar S, Mishra PR. Intranasal delivery: an approach to bypass the blood brain barrier. Ind J Pharmacol. 2004;36:140-7.

178. Dhuria SV, Hanson LR, Frey WH 2nd. Intranasal delivery to the central nervous system: mechanisms and experimental considerations. J Pharm Sci. 2010;99(4):1654-73.

179. Illum L. Is nose-to-brain transport of drugs in man a reality? J Pharm Pharmacol. 2004;56(1):3-17.

180. Illum L. Nasal drug delivery - recent developments and future prospects. J Control Release. 2012:161(2):254-63.

181. Johnson NJ, Hanson LR, Frey WH. Trigeminal pathways deliver a low molecular weight drug from the nose to the brain and orofacial structures. Mol Pharm. 2010;7(3):884-93.

182. Lochhead JJ, Thorne RG. Intranasal delivery of biologics to the central nervous system. Adv Drug Deliv Rev. 2012;64(7):614-28.

183. Illum L. Nasal drug delivery: new developments and strategies. Drug Discov Today. 2002;7(23):1184-9.

184. Bourganis V, Kammona O, Alexopoulos A, Kiparissides C. Recent advances in carrier mediated nose-to-brain delivery of pharmaceutics. Eur J Pharm Biopharm. 2018;128:337-62.

185. Thorne RG, Pronk GJ, Padmanabhan V, Frey WH 2nd. Delivery of insulin-like growth factor-I to the rat brain and spinal cord along olfactory and trigeminal pathways following intranasal administration. Neuroscience. 2004 127(2):481-96

186. Chapman CD, Frey WH 2nd, Craft S, Danielyan L, Hallschmid M, Schioth HB, et al. Intranasal treatment of central nervous system dysfunction in humans. Pharm Res. 2013;30(10):2475-84.

187. Frey WH, Liu J, Chen X, Thorne RG, Fawcett JR, Ala TA, et al. Delivery of 125I-NGF to the brain via the olfactory route. Drug Deliv. 1997;4:87-92.

188. Sakane T, Akizuki M, Yoshida M, Yamashita S, Nadai T, Hashida M, et al. Transport of cephalexin to the cerebrospinal fluid directly from the nasal cavity. J Pharm Pharmacol. 1991;43(6):449-51.

189. Anand Kumar TC, David GF, Sankaranarayanan A, Puri V, Sundram KR. Pharmacokinetics of progesterone after its administration to ovariectomized rhesus monkeys by injection, infusion, or nasal spraying. Proc Natl Acad Sci U S A. 1982;79(13):4185-9.

190. Wang $X$, He H, Leng W, Tang X. Evaluation of brain-targeting for the nasal delivery of estradiol by the microdialysis method. Int J Pharm. 2006;317(1):40-6

191. Striepens N, Kendrick KM, Hanking V, Landgraf R, Wullner U, Maier W, et al. Elevated cerebrospinal fluid and blood concentrations of oxytocin following its intranasal administration in humans. Sci Rep. 2013;3:3440.

192. Kristensson K, Olsson Y. Uptake of exogenous proteins in mouse olfactory cells. Acta Neuropathol. 1971;19(2):145-54.

193. Born J, Lange T, Kern W, McGregor GP, Bickel U, Fehm HL. Sniffing neuropeptides: a transnasal approach to the human brain. Nat Neurosci. 2002:5(6):514-6.

194. Anton F, Peppel P. Central projections of trigeminal primary afferents innervating the nasal mucosa: a horseradish peroxidase study in the rat. Neuroscience. 1991;41(2-3):617-28.

195. Thorne RG, Hanson LR, Ross TM, Tung D, Frey WH 2nd. Delivery of interferon-beta to the monkey nervous system following intranasal administration. Neuroscience. 2008;152(3):785-97.

196. Bilston LE, Fletcher DF, Brodbelt AR, Stoodley MA. Arterial pulsation-driven cerebrospinal fluid flow in the perivascular space: a computational model. Comput Methods Biomech Biomed Eng. 2003;6(4):235-41.

197. Hadaczek P, Yamashita Y, Mirek H, Tamas L, Bohn MC, Noble C, et al. The "perivascular pump" driven by arterial pulsation is a powerful mechanism for the distribution of therapeutic molecules within the brain. Mol Ther. 2006;14(1):69-78.

198. Schley D, Carare-Nnadi R, Please CP, Perry VH, Weller RO. Mechanisms to explain the reverse perivascular transport of solutes out of the brain. J Theor Biol. 2006;238(4):962-74

199. Lochhead JJ, Wolak DJ, Pizzo ME, Thorne RG. Rapid transport within cerebral perivascular spaces underlies widespread tracer distribution in the brain 
after intranasal administration. J Cereb Blood Flow Metab. 2015;35(3):37181.

200. Pires A, Fortuna A, Alves G, Falcao A. Intranasal drug delivery: how, why and what for? J Pharm Pharm Sci. 2009;12(3):288-311.

201. Harkema JR, Carey SA, Wagner JG. The nose revisited: a brief review of the comparative structure, function, and toxicologic pathology of the nasal epithelium. Toxicol Pathol. 2006;34(3):252-69.

202. Jansson B, Bjork E. Visualization of in vivo olfactory uptake and transfer using fluorescein dextran. J Drug Target. 2002;10(5):379-86.

203. Gross EA, Swenberg JA, Fields S, Popp JA. Comparative morphometry of the nasal cavity in rats and mice. J Anat. 1982;135(Pt 1):83-8.

204. Loscher W, Luna-Tortos C, Romermann K, Fedrowitz M. Do ATP-binding cassette transporters cause pharmacoresistance in epilepsy? Problems and approaches in determining which antiepileptic drugs are affected. Curr Pharm Des. 2011;17(26):2808-28.

205. Grewal GK, Kukal S, Kanojia N, Saso L, Kukreti S, Kukreti R. Effect of Oxidative Stress on ABC Transporters: Contribution to Epilepsy Pharmacoresistance. Molecules. 2017;22:3.

206. Romeo VD, de Meireles J, Sileno AP, Pimplaskar HK, Behl CR. Effects of physicochemical properties and other factors on systemic nasal drug delivery. Adv Drug Deliv Rev. 1998;29(1-2):89-116.

207. Schipper NG, Verhoef JC, Merkus FW. The nasal mucociliary clearance: relevance to nasal drug delivery. Pharm Res. 1991;8(7):807-14.

208. Graff CL, Pollack GM. P-glycoprotein attenuates brain uptake of substrates after nasal instillation. Pharm Res. 2003;20(8):1225-30.

209. Graff CL, Pollack GM. Functional evidence for P-glycoprotein at the nosebrain barrier. Pharm Res. 2005;22(1):86-93.

210. Graff CL, Pollack GM. Nasal drug administration: potential for targeted central nervous system delivery. J Pharm Sci. 2005;94(6):1187-95.

211. Graff $\mathrm{CL}$, Zhao R, Pollack GM. Pharmacokinetics of substrate uptake and distribution in murine brain after nasal instillation. Pharm Res. 2005;22(2): 235-44.

212. Westin U, Piras E, Jansson B, Bergstrom U, Dahlin M, Brittebo E, et al. Transfer of morphine along the olfactory pathway to the central nervous system after nasal administration to rodents. Eur J Pharm Sci. 2005;24(5): 565-73.

213. Dhuria SV, Hanson LR, Frey WH 2nd. Novel vasoconstrictor formulation to enhance intranasal targeting of neuropeptide therapeutics to the central nervous system. J Pharmacol Exp Ther. 2009;328(1):312-20.

214. Bennett DA, Lal H. Discriminative stimulus properties of the vasodilator, hydralazine: differential generalization with alpha 1 and alpha 2 adrenoreceptor drugs. Prog Neuro-Psychopharmacol Biol Psychiatry. 1982; 6(1):17-26.

215. Kamata K, Numazawa T, Kasuya Y. Vasodilator effects of clonidine on the mesenteric arterial beds in normotensive and spontaneously hypertensive rats. Res Commun Chem Pathol Pharmacol. 1994;84(3):371-4.

216. Holsti M, Sill BL, Firth SD, Filloux FM, Joyce SM, Furnival RA. Prehospital intranasal midazolam for the treatment of pediatric seizures. Pediatr Emerg Care. 2007;23(3):148-53.

217. Jenkins EK, DeChant MT, Perry EB. When the nose Doesn't know: canine olfactory function associated with health, management, and potential links to microbiota. Front Vet Sci. 2018;5:56.

218. Fernandez-Parra R, Pey P, Zilberstein L, Malve M. Use of computational fluid dynamics to compare upper airway pressures and airflow resistance in brachycephalic, mesocephalic, and dolichocephalic dogs. Vet J. 2019;253: 105392.

219. Schuenemann R, Oechtering G. Inside the brachycephalic nose: Conchal regrowth and mucosal contact points after laser-assisted turbinectomy. J Am Anim Hosp Assoc. 2014;50(4):237-46.

220. Kumar A, Pandey AN, Jain SK. Nasal-nanotechnology: revolution for efficient therapeutics delivery. Drug Deliv. 2016;23(3):681-93.

221. Mittal D, Ali A, Md S, Baboota S, Sahni JK, Ali J. Insights into direct nose to brain delivery: current status and future perspective. Drug Delivery. 2014; 21(2):75-86

222. Vidgren MT, Kublik $H$. Nasal delivery systems and their effect on deposition and absorption. Adv Drug Deliv Rev. 1998;29(1-2):157-77.

223. Warnken ZN, Smyth HDC, Davis DA, Weitman S, Kuhn JG, Williams RO 3rd. Personalized medicine in nasal delivery: the use of patient-specific administration parameters to improve nasal drug targeting using 3Dprinted nasal replica casts. Mol Pharm. 2018;15(4):1392-402.
224. Hardy JG, Lee SW, Wilson CG. Intranasal drug delivery by spray and drops. J Pharm Pharmacol. 1985;37(5):294-7.

\section{Publisher's Note}

Springer Nature remains neutral with regard to jurisdictional claims in published maps and institutional affiliations.
Ready to submit your research? Choose BMC and benefit from:

- fast, convenient online submission

- thorough peer review by experienced researchers in your field

- rapid publication on acceptance

- support for research data, including large and complex data types

- gold Open Access which fosters wider collaboration and increased citations

- maximum visibility for your research: over $100 \mathrm{M}$ website views per year

At BMC, research is always in progress.

Learn more biomedcentral.com/submissions 